\title{
La amenaza bélica de Corea del Norte y del Estado Islámico: un análisis sobre la eventual conflictividad planetaria desde el derecho internacional y las relaciones internacionales
}

The War Menace of North Corea and Islamic State: An Analysis on an Eventual Planetary Conflict from the Standpoint of the International Affairs

Miguel Ángel Rodríguez Mackay*

http://dx.doi.org/10.21503/lex.v15i20.1456

Internacionalista. Presidente del Instituto Peruano de Derecho Internacional y Relaciones Internacionales (IPEDIRI). Vicerrector de Asuntos Exteriores del Instituto Internacional de Gobierno (IIGOB). Exdecano de la Facultad de Derecho, Ciencia Política y Relaciones Internacionales de la Universidad Tecnológica del Perú. Miembro de la Sociedad Peruana de Derecho Internacional. Miembro de Número de la Academia Interamericana de Derecho Internacional y Comparado. Profesor de Derecho Internacional de la OEA. Profesor de Política Internacional de la Universidad Nacional Mayor de San Marcos y en la Academia Diplomática del Perú. Profesor de Derecho Internacional en la Universidad Alas Peruanas y de Política Internacional Latinoamericana en la Universidad San Ignacio de Loyola (USIL).

Correo electrónico: miguelangelrodriguezmackay@gmail.com; m_rodriguez_m@doc. uap.edu.pe

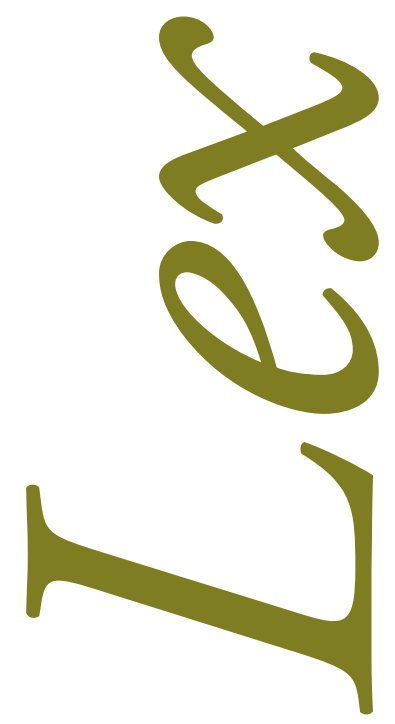




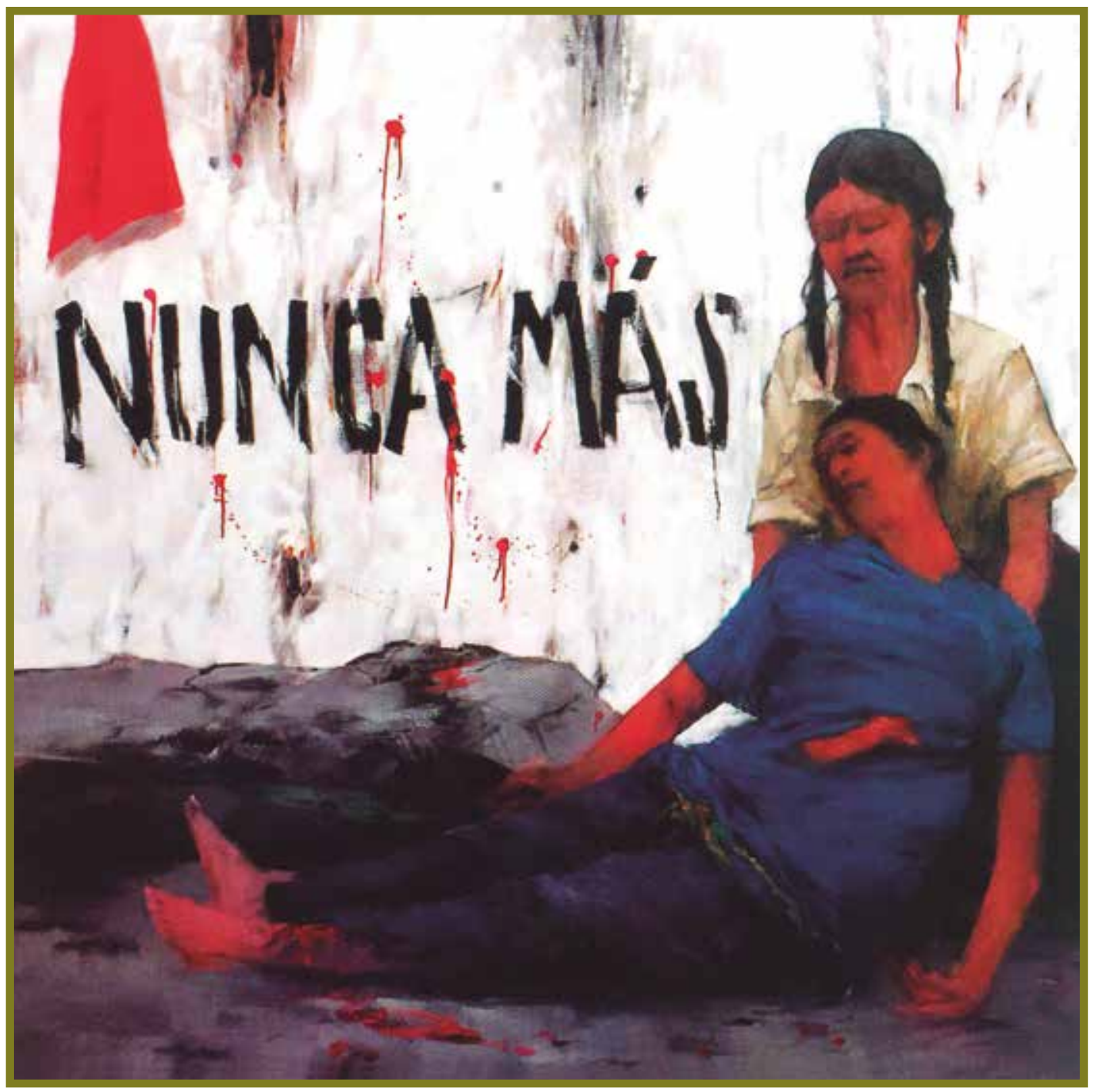

Raúl Cárdenas. Nunca más. 150 x 150 cm. 


\section{RESUMEN}

No es un título subjetivo. El sistema internacional es dinámico y heterogéneo y en ese marco la ciencia de las relaciones internacionales actúa para comprender los fenómenos internacionales que se producen en el referido sistema internacional. Desde los tiempos de la paz de Westfalia, el mundo ha experimentado procesos diversos acerca de cómo ha sido el comportamiento de los actores del sistema internacional. Gran parte de la historia de la comunidad internacional es la historia de los actores, los que clásicamente han sido los convencionales. El mundo de la interdependencia en que vivimos penetrados en el siglo XXI ha visto trastocado este clásico proceso internacional por la aparición de actores de construcción disociada del sistema internacional a los que se denomina actores no convencionales que irrumpen en el sistema internacional alterándolo. Todo este devenir de actores convencionales y la aparición de actores no convencionales han creado una sociedad internacional de la expectativa. El ensayo desarrolla, entonces, a los dos actores dinámicos que intervienen en el mundo para calificarlo: Corea del Norte y su calidad de actor convencional y el Estado Islámico en su condición de actor no convencional. Las relaciones internacionales no los discriminan por su origen y más bien los estudian por sus resultados, aunque el derecho internacional cuestiona al primero y proscribe al segundo. El objeto del ensayo es profundizar la acción de dichos actores capaces de poder alterar el statu quo del sistema internacional no importando su fase embrionaria, sea producto del pacto universal o de una deformación del mismo. De allí que lo que buscamos es determinar si se trata de un estado de tensión internacional o si realmente se ha ingresado a una etapa de alteración del orden internacional imperante, no necesariamente dominante.

Palabras clave: Corea del Norte, Estado Islámico, derecho internacional, relaciones internacionales.

\section{ABSTRACT}

This is not a subjective title. The international system is dynamic and heterogeneous and in such frame the international affairs science acts in order to understand the international phenomena produced in the said international system. Since the Westphalia Peace times, the world experimented diverse processes about the behavior of the actors of the international system. Great deal of the international community's history is the history of its actors, who have classically been the conventional ones. The interdependent world in which we are living, has seen this classic international process impaired because of the appearance of actors dissociated from the international system called unconventional actors which burst in the system altering it. This succession of conventional actors and the appearance of unconventional ones created an international society of expectation. This paper addresses, then, the two dynamic actors intervening in the world to 
classify it: North Corea and its conventional actor status and the Islamic State on its unconventional actor status. The international affairs do not discriminate them due to their origins but instead studies them for their results although the international law questions the first and bans the second. The object of this paper is to deepen the action of these actors capable to alter the status quo of the international system notwithstanding its embryonic stage be it a product of the universal pact or from its deformation. Thus we look to determine if it is an international tension status or if it has really entered a stage of alteration of the imperative international order but not necessarily dominant.

Key words: Corea del Norte, Islam State, international law, international affairs. 


\section{INTRODUCCIÓN}

El mundo ha venido acusando un estado de tensión internacional en las últimas semanas solamente comparable a la incertidumbre vivida en el globo en 1963 durante la crisis de los misiles entre Estados Unidos y la entonces Unión Soviética en la plenitud de la denominada Guerra Fría. ${ }^{1}$ La diferencia con aquel episodio son los años transcurridos que han permitido un desarrollo nuclear inimaginable, de modo que solamente sospechar la inminencia de una tercera guerra mundial sería el principio del fin de la humanidad o, si prefiere, el punto de quiebre de la involución de la sociedad internacional. Ningún afán alarmista debe imperar en las líneas de este ensayo para tan prestigiosa revista de la Facultad de Derecho y Ciencia Política de la Universidad Alas Peruanas (UAP).

Solamente el análisis del comportamiento de los actores visibles de las relaciones internacionales, la ciencia que estudia los fenómenos conflictuales y los procesos de carácter internacional que tienen impacto en el comportamiento del mundo y que en gran medida van decidiendo el decurso de la humanidad, ${ }^{2}$ nos puede dar luces para la reflexión que iniciamos.

Los sucesos en Siria donde el régimen del dictador Bashar al-Assad ha sido imputado responsable de lanzar gases tóxicos contra poblaciones civiles en la idea de que lo hacía contra grupos rebeldes o terroristas y la reacción estadounidense, decidida al margen del derecho internacional, de bombardear una base militar del Gobierno sin consentimiento del Consejo de Seguridad de la ONU, así como la inesperada acción militar aérea de EE.UU. de bombardear posiciones del Estado Islámico en Afganistán, uno de los países que, junto a Pakistán, cuenta con la mayor cantidad de terroristas en el planeta, en la idea de neutralizarlos, han terminado por llevar a Washington y a Moscú, como siempre actores exógenos de los problemas directos de esa región, a una suerte de rivalidad que por supuesto en nada se parece a la que sostuvieron en los tiempos de la Guerra Fría.

Robert J. Mcmahon, La Guerra Fría: una breve introducción (Alianza Editorial, 2009), 304.

2 James E. Dougherty y Robert L. Pfaltzgraff, Teorias en pugna en las relaciones internacionales (Buenos Aires: Grupo Editor Latinoamericano, 1993), 197-224. 
Pegado a estos sucesos yace la amenaza permanente que representa el régimen de KimJong-un de Corea del Norte, que ha realizado el lanzamiento de un misil balístico de alcance intercontinental que comienza a provocar seriamente a Estados Unidos, y por supuesto el anuncio de la inminencia de un ataque contra su mayor enemigo y el más vulnerable: Corea del Sur.

El panorama internacional es de calificarse de un típico estado de tensión internacional, dado que puede escalar para convertirse en un estado bélico planetario, lo que nadie en su sano juicio realmente quiere.

Están llamando poderosamente la atención las últimas decisiones de la Casa Blanca, cuyo inquilino, Donald Trump, convertido en el $45^{\circ}$ presidente de los Estados Unidos de América, pregonó a los cuatro vientos, cuando candidato, una crítica de lo que habían hecho los expresidentes Bush y luego Barack Obama en el complejo asunto del Medio Oriente. Todo ese discurso que también fue apreciado por un sector de estadounidenses es cuestión del pasado, pues Trump parece estar decidido a valerse de acciones militares para imponer reglas y transmitir al mundo la idea de que Washington sigue siendo el superpoder militar del planeta.

Trump hará cualquier cosa para que, desde su lectura, le quede claro al mundo que EE.UU. es la única nación hegemónica del globo y no se va a detener en mostrarlo por las narices de los actores convencionales (China, Rusia, Irán, Corea del Norte, Siria, etc.), así como los no convencionales, es decir, aquellos que están actuando al margen de las normas jurídicas del derecho internacional, como es el caso de los grupos terroristas que operan a sus anchas básicamente en la región del Medio Oriente.

EE.UU. le ha hecho saber a Rusia acerca de la necesidad de evaluar su alianza con el régimen sirio y, por tanto, adoptar una decisión sobre el dictador Al-Assad en la idea de que se trata de un interlocutor agotado con el que ya no se podrá efectuar ninguna negociación que permita superar la crisis en ese país. Mientras Rusia no decida en esa línea, desnudará sus verdaderas intenciones de no querer dejar por ningún motivo su calidad de potencia regional que le permite mantener su base naval en este país, pero sobre todo sostener su radio de influencia en la exacta dimensión de que lo persigue EE.UU. No sabemos cuánto lo va a tolerar Washington, que hace rato le ha bajado el dedo al presidente sirio.

Pero el Medio Oriente no es solo el problema de Siria, también lo es el asunto entre Israel y Palestina por el permanente asunto de los territorios árabes que los judíos han tomado por la fuerza y que no son capaces de devolver. A pesar de que las Naciones Unidas en 1947 emitió la Resolución 181 sobre la partición de Palestina, creando dos Estados: Israel y Palestina, dichos territorios siguen siendo objeto de disputas de nunca acabar. La escalada a una etapa bélica en el Medio Oriente y la región asiática en general, como vemos, es una posibilidad que no se puede descartar. Es verdad que los actores son diversos y que un conflicto a estas 
alturas solamente traerá desolación a la humanidad. De allí que será clave que la diplomacia juegue su partido. Cualquier distracción sobre la seguridad planetaria puede tener consecuencias catastróficas para el destino del mundo; hay que decirlo sin caer en el irresponsable alarmismo.

\section{LA SOLUCIÓN PACÍFICA DE CONTROVERSIAS COMO REGLA}

La solución pacífica de las controversias consagrada como principio de carácter imperativo en el mundo es la regla que debe conducir el destino de los países. ${ }^{3}$ La obsecuencia puede tirarla al tacho, también es verdad. De allí que todos los directa o indirectamente concernidos en la paz del mundo tienen una cuota de responsabilidad que asumir y cumplir. Las relaciones internacionales se deciden por hombres que son los actores visibles y que están llamados imperativamente a mostrarse cuerdos; de lo contrario, cualquier desgracia podría suceder. El asunto es que los actores visibles como Kim Jong-un, Donald Trump, Bashar al-Assad, etc., no parecen ser ninguna garantía de una paz permanente, como lo manda la Carta de San Francisco.

Estamos viviendo en el mundo de las amenazas. A eso técnicamente se le denomina desde el derecho internacional, que es el mundo de las normas jurídicas internacionales, coerción, $\mathrm{y}$ desde las relaciones internacionales y defensa, que es el mundo del poder y los fenómenos conflictuales, disuasión. En la práctica, la amenaza logra su cometido: crear un estado de alerta e incertidumbre internacionales que impactan al principio de la paz internacional, que constituye el mayor deber de la sociedad internacional desde la creación de la ONU, en 1945. Mientras Corea del Norte muestra en el marco de un impresionante desfile militar sus eventuales potenciales armas nucleares, expresando sus voceros sin descanso que están preparados y listos para efectuar un ataque a gran escala, primero contra Corea del Sur o Japón, y luego contra EE.UU., Washington no se queda atrás y la Casa Blanca de un tiempo a esta parte también ha caído en el mismo juego que el dictador norcoreano Kim-Jong-un, para anunciar a los cuatro vientos que no tolerarán una sola acción bélica de Pyongyang, y que, en consecuencia, actuarían sin pensarlo dos veces.

Así las cosas, la comunidad internacional es la que más sale perdiendo porque termina estresada y ya corren titulares anunciando la tercera guerra mundial. La finta norcoreana se acabará en el momento en que China decida bajar el dedo y corte el caño a su antiguo aliado —desde los tiempos de la guerra de Corea de 1953 —, manteniéndolo airoso hasta ahora. El impacto de una medida económica no hay fórmula que la resista, pues la economía de Pyon-

3 Miguel Ángel Rodríguez Mackay, "El principio de solución pacífica de controversias como norma de ius cogens del derecho internacional y los medios de solución de controversias internacionales", en XLI Curso de Derecho Internacional 2014, dictado por el autor en el Comité Jurídico Interamericano de la Organización de los Estados Americanos (OEA), en Río de Janeiro, 15 de agosto de 2014 (Washington D.C.: Secretaría General de la OEA, 2015), 229-260. 
gyang es absolutamente dependiente de la china, y Kim-Jong-un lo sabe. Ese escenario podría moverle el piso a Jong-un y podría germinar las disidencias para muchos aún impensables. La mayor amenaza a la vista y que podría desestabilizar a Washington será, pegado a Corea del Norte, la reacción de yihadismo luego del certero ataque decidido por Donald Trump en sus posiciones en Afganistán.

El panorama internacional por los últimos sucesos en el Medio Oriente, particularmente en Siria, entonces, es ideal para analizar el comportamiento de los actores visibles de las relaciones internacionales. En primer lugar, más allá de que EE.UU. haya actuado al margen del derecho internacional al haber bombardeado unilateralmente una base militar siria, es decir, sin aprobación del Consejo de Seguridad de la ONU, que es el órgano de las Naciones Unidas llamado a preservar la seguridad del mundo, lo cierto es que Washington está imponiendo su cuota hegemónica. A los bombardeos sobre posiciones del régimen de Bashar al-Assad, ha seguido una impresionante movilización de sus portaviones en los mares del Asia, particularmente cerca de las costas de Corea del Norte, el otro dolor de cabeza para EE.UU.

El poder de EE.UU. está fundado en su insuperable fuerza militar, pues ningún país del globo se parece a Washington en esa condición. Ese poderío supone una conducta como la del secretario de Estado, Rex Tillerson, que prácticamente ha conminado a su homólogo ruso a que desista de su alianza estratégica con el régimen de Damasco. No sabemos aún si lo logrará porque Moscú no está dispuesto a perder un aliado dinámico para su proyección geopolítica en el Medio Oriente, mirando el Mediterráneo y la Unión Europea.

Por otro lado, Beijing ha manifestado que no quiere ningún escenario conflictual a la vista y que hará cualquier cosa por evitarlo. Los chinos apostaron por el desarrollo de una economía de mercado desde los tiempos de Deng Xiaoping, de allí que buscarán indesmayablemente que no se alteren sus planes comerciales. Quieren ser un gran imperio económico y solo esperan pacientes que la historia los avale por la teoría de la ciclicidad del poder. Mientras tanto, es verdad que Moscú y Beijing tienen lo suyo, pero siguen mostrando una condición voluntariamente subordinada a discreción al poder de EE.UU.

\section{LA DINÁMICA CONFLICTUAL INTERNACIONAL}

Mirando el mundo, entonces, con una coyuntura planetaria tensionada, precisemos que no estamos en una tercera guerra mundial. La mejor definición dice que es una conflagración bélica a escala planetaria donde intervienen diversos actores (países) de distintos espacios geográficos. Suelen enfrentarse con fuego, formando bloques o alianzas.

Desde el alba de la civilización hasta la actualidad hubo un sinnúmero de conflictos, pero de carácter local o regional sin llegar al tamaño de guerra mundial, con excepción de las dos guerras mundiales del siglo XX. 
Son célebres las guerras Púnicas, las guerras Médicas, las guerras del Peloponeso, la guerra de Troya, las guerras Dóricas, las guerras Itálicas, la guerra de las Galias, la guerra de las Cruzadas, la guerra de los Treinta Años, la guerra de los Cien Años, la guerra de Lepanto, las guerras Napoleónicas, la guerra del Chaco, la guerra del Pacífico, la guerra de Corea, la guerra de Vietnam, la guerra del Golfo Pérsico, la guerra de Irak, etc.

Ninguno de los conflictos referidos tuvo alcance universal. Solamente la primera (19141918) y la segunda (1939-1945) guerras mundiales son consideradas en esa dimensión por su carácter e impacto universal. En la guerra de 1914 se formó la Entente Cordiale (Reino Unido, Francia, Rusia y EE.UU.) y la Triple Alianza (Alemania, Italia y Austria-Hungría), y durante la guerra de 1939 se agruparon los Aliados (EE.UU., Rusia y Reino Unido) y el Eje (Alemania, Italia y Japón). Es verdad que en el reciente escenario podríamos ensayar hasta dos bloques: a) Coalición: EE.UU., Reino Unido, Francia, Alemania, Japón, Israel, Corea del Sur, Arabia Saudí, Taiwán, España, etc., y b) Bloque Oriental: Rusia, China, Irán, Corea del Norte, Siria, etc.), pero a diferencia de los conflictos ciclópeos del siglo XX, por el impresionante desarrollo nuclear de los Estados, una tercera guerra no podría contar librada a la humanidad. Del estado prebélico actual, técnicamente tensión internacional, solo queda retroceder para que, con sensatez, actúe la diplomacia; de lo contrario, seguirá inexorable la involución del hombre.

Las relaciones internacionales lo explican, pero no lo solucionan porque es un asunto que se asocia a la dinámica del poder internacional, sea convencional o no convencional, una realidad contrario sensu frente a la heterogeneidad que existe en la visión clásica de la sociedad internacional. ${ }^{4}$

Por ejemplo, en nuestro enfoque, en el imaginario colectivo de los estadounidenses, pero en general de la sociedad internacional contemporánea, la sola mención del grupo talibán produce dos cosas: rechazo total y temor porque vuelvan a actuar como en el 2001, cuando coludidos con Al Qaeda brindaron todo el soporte a su jefe ya desaparecido, Osama Bin Laden, para realizar el mayor atentado terrorista de la historia contemporánea que cambió la dinámica del devenir del mundo y radicalmente el enfoque de la política exterior de los EE.UU., y, en consecuencia, los paradigmas de las relaciones internacionales, al traerse abajo Al Qaeda las Torres Gemelas de Nueva York, aquel 11 de setiembre de 2001.

En un ataque aéreo con drones o aviones no tripulados durante el mes de abril de 2017, Estados Unidos eliminó al Mullah Akhtar Mansour, el líder de los talibanes afganos. Se había propinado al grupo talibán una de sus mayores fragmentaciones de las que ya viene soportando desde que fue muerto el Mullah Mohammad Omar, su líder fundador, hace ya más de tres

4 Esther Barbé, Relaciones internacionales, tercera edición (2007), 137-140. 
años, también por Washington. La Casa Blanca es consciente de que no puede dar ninguna tregua a los talibanes - Barack Obama antes y ahora Donald Trump-, y sus asesores lo saben muy bien y por eso el nuevo presidente no ha vacilado en autorizar el bombardeo que todos vimos, pues la capacidad de recomposición yihadista es extraordinaria, facilitada por contar con un espacio idóneo en que actualmente vienen movilizándose, como es la región pastún, fronteriza entre Pakistán y Afganistán, prácticamente infestada de grupos extremistas.

Reacios a Occidente en todo, los talibanes — que en su origen refiere a estudiantes instruidos en las ciencias islámicas - son de tradición sunní, y reconocidos como escrupulosos obedientes de las normas y rituales derivados del dogma islámico. En ascenso al poder a fines de los noventa luego del fracaso del nacionalismo árabe y el final de la Guerra Fría, pregonaron devolverle al islam sus principios originarios (salafiya). Como enemigos de los chiitas, la otra rama del islam, jamás vieron con buenos ojos a Irán, el país con mayor número de esta minoría islámica. Con lo anterior, Washington no los pierde de vista, pues aunque por ahora sus vinculaciones con el Estado Islámico, también sunní, son carentes de registro estructurado, no pueden fiarse de nada.

El descalabro humanitario por el conflicto en el Medio Oriente ha generado la reacción del nuevo secretario general de la ONU, el portugués Antonio Guterres, que a su turno condenó el inmisericorde bombardeo sobre un hospital en la zona de Alepo, uno de los territorios más devastados tanto por parte de los actores convencionales - como es el caso de las fuerzas del régimen de Bashar al-Assad - como de los rebeldes que buscan la salida del dictador, y con estos, los actos sanguinarios de los grupos terroristas que buscan profundizar la desestabilización del país, como sucede con el Estado Islámico.

La gravedad del asunto pasa porque ha sido el propio representante del mayor foro político del planeta quien no ha dudado en imputar a Rusia responsabilidad por asociación en los ataques perpetrados por el régimen sirio en un nosocomio causando la muerte de personas en una clarísima muestra de desdén de las reglas del derecho internacional humanitario. En efecto, los Convenios de Ginebra de 1949 y sus protocolos complementarios que establecen la prohibición de atacar a los civiles o a las posiciones en que se encuentren, siempre en medio del combate, han sido ninguneados.

Lo anterior impacta en una de las mayores garantías internacionales consagradas históricamente en el derecho de la guerra. Guterres sabe de la magnitud de este tipo de atropellos y por eso ha calificado el nefasto ataque de "imperdonable". Rusia por supuesto lo ha negado. Sabe que este tipo de acciones al margen del derecho tarde o temprano podrían promover niveles de responsabilidad penal individual en el marco de la Corte Penal Internacional.

Pero nuestro objeto central no está dedicado a uno que otro caso exponencial del terrorismo yihadista tan solo para condenarlo. No. Nuestro análisis busca la profundidad y debemos 
valernos para ello de los casos que impactan en el marco de la comunidad internacional, eso es verdad.

Con lo anterior, nadie puede olvidar el atentado en el barrio chiita de Sayeda-Zeinab, en Damasco, la capital de Siria, por extremistas de origen sunita del Estado Islámico - le ha seguido a otro en febrero de 2017 en que murieron cerca de 120 personas-, lo que reconfirma la milenaria rivalidad entre chiitas y sunitas, las dos ramas principales del islam, que no se ha detenido desde la muerte de Mahoma, el profeta mayor de la religión islámica, en el $632 \mathrm{~d}$. C.

Sus seguidores lidiaron para determinar quién tendría el liderazgo de su sucesión. Así comenzó la historia de la división del islam entre sunitas y chiitas, en la idea de formar el Gobierno del califato islámico. Los chiitas creen que debe serlo un familiar de Mahoma —el caso de Alí, su primo y yerno- por designación de gracia divina. Los sunitas, en cambio, consideran que el sucesor debe ser elegido por la mayoría de la comunidad musulmana —su histórica figura fue Abu Bakr, suegro de Mahoma-, conforme los extractos de la Sunna, libro sagrado que contiene las palabras de los profetas y sus seguidores, de allí que se denominen sunitas. Estos, que son mayoría, representan alrededor del $87 \%$ de musulmanes en el mundo (en total: 1500 millones), mientras que los chiitas llegan al $13 \%$. Países sunitas a confesión son Arabia Saudita, Afganistán, Pakistán, Kuwait, Yemen, Egipto, Túnez, Libia, Turquía, Siria, mientras que chiitas se cuenta a Irán, Irak, Líbano y Palestina. Las subramas sunitas más relevantes son los wahabitas (salafitas), mientras que las chiitas reconocidas son los imamíes, alauitas, ismaelitas y zaidíes. Los grupos extremistas islámicos que nunca deben asumirse como si fueran parte de la religión del islam también se confunden entre sunitas (Al Qaeda, Hamas, Talibán, Estado Islámico, Hermanos Musulmanes) y chiitas (Hezbolá, Hamás).

\section{LOS ACTORES NO CONVENCIONALES DE LAS RELACIONES INTERNACIONALES}

La naturaleza no convencional de los actores de las relaciones internacionales que denominamos terroristas nos exige un nivel de precisión conceptual. En efecto, para que un acto sea considerado terrorista no tiene que ser atribuido necesariamente a una organización extremista. Es a lo que más estamos acostumbrados escuchar o identificar, pero no es solo eso. El atentado en Niza del 16 de julio de 2016 se parece y mucho al de Orlando (12 de junio de 2016), es decir, sus autores no tienen ninguna relación directa con los grupos terroristas conocidos como Al Qaeda o el Estado Islámico, ni tampoco cuentan con una logística propia de las bandas del terror. Tampoco los recientes en Londres. Al contrario, salta a la vista un cuadro más bien personal o unilateral donde se trasluce sin dificultad una afinidad o adhesión con el islam. Por supuesto que los terroristas islámicos no tienen nada que ver con los fieles musulmanes que son gente de paz. Tan solo el $1 \%$ de los más de 1500 millones de islámicos 
que existen en el mundo son considerados fundamentalistas extremistas. La religión, aunque no es el tema central, aparece con notable evidencia en los atentados que se han venido cometiendo.

Los terroristas, a los que no les importa la vida ni las normas jurídicas, suelen invocar la figura de Alá, el dios del islam y la de Mahoma, su profeta mayor. Esta es la primera desnaturalización del verdadero sentido de la religión musulmana y del Corán, su libro sagrado y de un auténtico contenido de amor y paz. ${ }^{5}$ La respuesta de la comunidad internacional otra vez será únicamente la acción militar en el marco de la coalición internacional que lidera EE.UU., y eso sí sería un nuevo y grave error. Hay que ir al asunto de fondo, lo que significa acabar con las posiciones extremistas y antioccidentales. En esta tarea deberá haber una acción comprometida de la Liga Árabe y por supuesto de la ONU. El mundo está enfrentando una guerra o conflicto distinto a los que hubo 2000 años atrás, es decir, con un actor no convencional y que opera de modo anárquico, sin que le importen las reglas de la convivencia humana.

Pero con todo lo anterior, mucho se escribe y poco se entiende sobre los conflictos en el Medio Oriente tildados de nunca acabar. Una mirada hacia adentro podría ayudarnos a comprender las complejidades que los han generado. El mundo del islam, rico en historia y en cultura, ocupa el centro del análisis. Esta religión surgió al credo internacional con Mahoma, el profeta elegido, que la afirmara luego del viaje de huida que realiza desde La Meca hacia Medina en el 622 d. C., lo que se conoce en la historia universal como la Hégira. El islam es la religión dominante entre los árabes y en muchos países asiáticos.

A la muerte del profeta, fue elegido su suegro Abu Baker como primer califa de los cuatro en la fase gestacional del islam en la región arábiga. Cuando sobrevino la muerte al tercer califa Uthman ibn Affan, el primo y yerno de Mahoma, Alí, que tuvo que esperar cerca de 30 años, fue reconocido como el cuarto califa. Su liderazgo espiritual fue corto - apenas cuatro años- y a su muerte sus partidarios, los chiitas, propugnaban porque sea un descendiente directo de Mahoma el que fungiera de nuevo líder del islam.

En la otra orilla, se hallaron los sunitas, la otra rama del islam, que pregonaban que debía serlo un hombre estudioso y justo capaz de recoger las tradiciones y enseñanzas de Mahoma. Desde ese momento, las rivalidades entre chiitas y sunitas no se han detenido; sin embargo, no puede afirmarse que el problema histórico y actual sea un asunto enteramente religioso, porque, con sus matices y complejidades, ambas ramas del islam creen en el mismo dios, que es Alá, tienen el mismo profeta que es Mahoma y cultivan imperturbablemente, además, la oración, el ayuno y la peregrinación a La Meca, la que realizan por lo menos durante una vez en la vida.

5 Alí Unal, El sagrado Corán y su interpretación comentada (Nueva Jersey: La Fuente, 2009). 
Hay dos hechos que para la mayoría de los estudiosos habrían desencadenado continuas pugnas dentro de algunos países musulmanes o entre estos. El primero, referido a la revolución islámica de 1979 en Irán — de población mayoritariamente chiita— que encabezó el ayatola Jomeini y que promovió una doctrina radical contra los sunitas; y la segunda, la invasión de los Estados Unidos a Irak el 2003 — también con mayoría chii-, bajo el pretexto de combatir la amenaza internacional del terrorismo y desmantelar el arsenal de armas químicas que nunca se encontró, agravando las rivalidades históricas entre ambas ramas del islam y alterando de alguna manera el modus vivendi entre los árabes.

Si uno revisa con atención los Gobiernos que mantienen el poder en estos países en fase de conflictos permanentes, independientemente del tipo de régimen o de su carácter político o ideológico, advertirá que la regla se cumple, es decir, cual rama del islam lo detente ya mismo será objeto de oposiciones y de conspiraciones por la otra. Mirando lo más cercano a la coyuntura, por ejemplo, en Siria donde, la población es mayoritariamente sunita, el Gobierno de Bashar al-Assad, alauita, una secta chiita, enfrenta una encarnizada oposición de grupos extremistas de origen sunita. En Irak pasa algo parecido, pues, donde la mayoría de sus habitantes es de origen chiita, está enfrentando por estos días la amenaza de grupos aislados radicales sunitas que quieren recobrar el poder que tuvieron desde 1979, en que su líder, Sadam Hussein, fue elegido presidente hasta su derrocamiento en el 2003.

El problema de fondo tiene que ver, entonces, con un asunto de grandes complejidades en las relaciones entre Gobierno y religión, y como hemos visto, aun cuando los chiitas representan la minoría en el islam, resulta clave para el análisis que al no serlo en Irak e Irán y solventar el poder, las revueltas de grupos sunitas harán cualquier cosa por verlos defenestrados, y en el caso de Siria — repito-, más complicado todavía porque la oposición de grupos como el Estado Islámico de Irak y el Levante, que es sunita, quiere acabar con la minoría alauita (chií) gobernante. Será, pues, un asunto que pasa por la incapacidad de sostener y tolerar unos a otros en la administración del poder porque el proceso histórico confesional los ha enfrentado todo el tiempo, haciéndolos vulnerables y lamentablemente irreconciliables.

Como bien ya se ha anotado, no es un secreto la milenaria situación conflictual entre sunitas y chiitas, aunque ello pueda crear la idea de una crisis dentro del propio islam. ${ }^{6}$ Los atentados en Bangladesh (2 de julio de 2016) lo confirman. Los grupos fundamentalistas, de origen sunita o chiita, vienen creado una alarma internacional. Por ejemplo, el poderoso Estado Islámico que opera entre Siria e Irak, principalmente, y que es de origen sunita, ha venido cometiendo ataques suicidas en comunidades chiitas y sin ningún tipo de compasión. Junto a esta animadversión manifiesta, el chiita Hezbolá, grupo extremista libanés, condenó el atentado del Estado Islámico en Irak, advirtiendo venganza.

6 Bernard Lewis, La crisis del islam: guerra santa y terrorismo (Barcelona: Ediciones B, 2003), 27-51. 
Es verdad que también operan violentamente contra los extranjeros que no son musulmanes, preferentemente llegados a esas lejanas tierras desde Occidente, los que, por no saber recitar las aleyas o versos del Corán, son reducidos a la calidad de infieles e inmediatamente eliminados. Más allá de las acciones militares que realiza la referida coalición internacional de más de 40 países liderados por EE.UU. para acabar con el Estado Islámico, el fondo del problema no será resuelto de esa única manera. La intolerancia y el fanatismo que surgen en las porciones extremistas desnaturalizando el verdadero sentido y mensaje de la religión fundada por Mahoma, el profeta mayor, en el 622 d .C., son de los mayores obstáculos para vencerlos. Los centros de altos estudios islámicos regentados por importantes universidades de países del Medio Oriente, como Al-Azhar de Egipto, deberían desarrollar planes para enseñar el único y verdadero sentido de amor que profesa el islam, cronológicamente la tercera religión monoteísta más importante en aparecer en el mundo. El terrorismo no es religión, pero muestra un pretendido sesgo introducido en ella para justificar sus actos.

Con lo anterior, la foto del mundo es para preocuparse. Al referido ataque de Estados Unidos a una base militar del régimen del dictador sirio Bashar al-Assad luego de que le fuera imputado lanzar un ataque con armas químicas sobre población civil e indefensa, y al desplazamiento de un portaviones, el más poderoso y letal que cuenta en la región asiática, movilizándolo hasta las costas próximas a Corea del Norte, Washington, entonces, ha sorprendido al mundo con un certero ataque aéreo con bomba no nuclear pero efectiva en Afganistán, cerca de la frontera con Pakistán, en la región asiática, contra posiciones del Estado Islámico en espacios subterráneas clandestinos.

Debemos insistir que EE.UU. sabe que en Afganistán —-desde donde Al Qaeda, coludido con el régimen talibán, atacó las Torres Gemelas, en setiembre de 2001- se encuentra la cuna del terrorismo internacional. Allí se gestan y de allí parten los ataques hacia sus objetivos. La CIA debe haber identificado las vinculaciones del Estado Islámico, surgido de los escombros de Al Qaeda, a la muerte de Osama Bin Laden (2011), con los últimos remanentes del referido grupo terrorista. La inteligencia estadounidense sabe muy bien que no les puede dar espacios a los yihadistas, y por esa razón arremete por resultados.

En ese contexto, el verdadero rostro de Donald Trump en estos seis meses de gobierno comienza a revelarse en toda su extensión. Su discurso de los tiempos de candidato es cuestión del pasado. Les dice a los actores concernidos de las relaciones internacionales en el clima de tensión internacional desatado (Rusia, Corea del Norte, Irán, Siria, Afganistán, China, etc.) que el realismo político prima sobre todas las cosas.

No se trata de ingresar en el desarrollo de las corrientes o doctrinas de las relaciones internacionales que sustentan los casos o hechos fácticos que en una revista de este prestigio también podría abordar, sino, en cambio, encontrar en la narración de hechos incuestionables, las 
raíces del nuevo problema que enfrenta la humanidad, con un orden internacional que puede estar en riesgo. La actitud estadounidense, entonces, sería pura actitud para mostrar hegemonía. En ese marco, se trata de una crisis internacional atípica, pues además de los referidos actores convencionales están los no convencionales, donde se ubica el terrorismo internacional al que ya estoy refiriendo ad hoc. Así las cosas, existe un panorama prebélico cuya escalada se debe evitar a cualquier precio. La diplomacia tiene que mostrarse para que la paz de la Carta de San Francisco (ONU, 1945) sea la regla; pero esto último lo desarrollaré más adelante.

Pegado a lo anterior está signando transversalmente la intransigencia del presidente Donald Trump con su visión particular de la política exterior estadounidense sobre los musulmanes, impidiéndoles ingresar en el país, aunque hasta dos jueces le han trabado su particular iniciativa. Para Trump, los acontecimientos violentos en los países islámicos es razón suficiente para poner coto a su ingreso en los Estados Unidos. La realidad internacional, al fin y al cabo, es una sola e ineludible: violencia extremis desde cualquier origen, que es lo más trágico. Lo que sucedió en la localidad de Jan Sheijún, al norte de Damasco, capital siria, una zona controlada por grupos rebeldes al régimen de Bashar al-Assad y yihadistas, donde se han utilizado armas químicas ahora imputadas al Gobierno — que lo niega en todo momento-, constituye una flagrante violación de los convenios internacionales que proscriben su uso. Luego de la Segunda Guerra Mundial, en que el mundo había experimentado cuán letal había sido el uso de las bombas nucleares sobre las ciudades de Hiroshima y Nagasaki por parte de EE.UU., se proclamó de mil maneras el rechazo al uso de cualquier tipo de armas no convencionales.

A la dación de los Convenios de Ginebra de 1949, que fueron los primeros consensuados sobre el derecho de los conflictos armados y que definió que en la guerra no era cierto que todo vale, luego fue aprobada la Convención sobre las Armas Químicas, que entró en vigor en 1997, cuyo mandato desde esa fecha ha sido la erradicación para siempre del flagelo de este tipo de armas y de verificar la destrucción, en los plazos establecidos, de los arsenales de armas químicas declarados. Usarlas, como parece ser que lo hizo Siria, mereció la mayor condena internacional, configurando responsabilidad internacional por sus consecuencias.

Es el momento de la ONU para que pueda determinar dicha responsabilidad, que ahora todos los directa o indirectamente involucrados en el conflicto niegan categóricamente. Se calcularon en más de 70 las víctimas — varios niños- en aquel ataque perpetrado el 7 de abril de este año. El régimen sirio fue condenado por toda la comunidad internacional, y para Al-Assad, que no está del todo librado, si resultara responsable, su suerte podría llevarlo a un fin como el de Saddam Husein, que por ensañarse con los kurdos (1989) y los chiitas (2003) iraquíes, utilizando armas químicas, terminó ahorcado por un tribunal chiita. Mientras los Estados involucrados en la guerra de Siria dicen que no son autores del macabro ataque, el Consejo de Seguridad de la ONU hasta ahora no ha podido ponerse de acuerdo para condenar el ataque debido a la frontal oposición de Rusia. 
Moscú sabe qué sí debe condenar y qué no. Vamos al reporte de los hechos. Ningún Estado está libre de un ataque terrorista. Rusia tuvo que soportar un vil atentado registrado en la ciudad de San Petersburgo, la segunda ciudad más importante de ese país, también en abril de 2017. La pregunta que todos se hacen es por qué razón Rusia, un país geográficamente lejano de Occidente, tradicional escenario de asaltos y ataques del terrorismo islámico. Vladimir Putin, presidente ruso, que había llegado a la ciudad donde sucedió el atentado para sostener una reunión con su homólogo de Bielorrusia, terminó de convencerse que el terrorismo no solo le ha puesto la puntería a los Estados Unidos o a Europa, sino también a su país, que, aliado del régimen de Bashar al-Assad, arreció contra las porciones del Estado Islámico que se hallaban en la ciudad de Alepo, empoderando nuevamente al dictador sirio y a su Gobierno.

Ningún Estado es invulnerable al desalmado y amorfo sistema no convencional que ha aparecido en el mundo sin consultar a los actores visibles o tradicionales de las relaciones internacionales. De allí que el ataque en el metro de San Petersburgo puso en alerta a los rusos, que no pudieron salir de su asombro. El acto terrorista los cogió de sorpresa. En diciembre de 2016, el embajador ruso en Turquía fue abatido. Los sucesos recientes, entonces, no son obra de la casualidad. Está claro que Rusia también se ha convertido en un serio obstáculo para el Estado Islámico, y en esa idea los terroristas le han puesto la puntería para buscar desestabilizar al país más importante de la región euroasiática pero que también se ha convertido en un actor relevante — como en el pasado- de las relaciones internacionales.

Putin ha sabido manejar hasta ahora con notable destreza el liderazgo de Rusia en el ámbito regional, pero deberá admitir que siempre creyó que los ataques terroristas jamás serían dirigidos hacia su país, o por lo menos no por ahora. Cuánto quisiera reaccionar con la misma rapidez con que decidió la anexión de la península de Crimea (parte de la soberanía de Ucrania), pero el propio Putin sabe que eso tendrá que esperar. El atentado ha vuelto más vulnerable a Rusia, y eso no es nada bueno.

Pero la reacción rusa o estadounidense aun no es del todo medible por el derecho internacional, y convendría formularnos la siguiente pregunta: ¿cómo se explica que un país como EE.UU. actúe al margen del derecho internacional, aun cuando su accionar para algunos resultaría justificado dada la inhumanidad del régimen sirio de Bashar al-Assad, acusado de la muerte de más de 80 seres humanos, atacados con armas tóxicas, prohibidas por los convenios internacionales, lo que ya hemos referido. Seamos claros. Washington tenía muchas ganas de intervenir en Damasco, pues desde los tiempos de Barack Obama quiso bombardearla y derrocar al dictador Al-Assad.

En esa ocasión, el Consejo de Seguridad de la ONU no autorizó una acción militar aérea solicitada por el Gobierno estadounidense debido al veto de Rusia y China. Era previsible que en las actuales circunstancias de la guerra, en que Rusia, aliado estratégico de Damasco al 
coadyuvar militarmente con el régimen para recuperar la importante ciudad de Alepo — hoy en ruinas - y lograr empoderarse, una nueva solicitud — esta vez de Donald Trump— sería denegada. Por esa razón decidió recurrir al pragmatismo de su acción internacional para recuperar el espacio geopolítico de influencia perdido en Siria. Washington la ejerce sobre Arabia Saudí, el mayor productor de petróleo del planeta, sobre Irak, Egipto, Jordania, y hasta logró mediatizar de alguna manera a Irán por un acuerdo de programa nuclear.

Por otro lado, los rusos, que también pisotearon el derecho internacional anexando la referida península ucraniana de Crimea, no se quedan atrás. Ambos, Washington y Moscú, son actores convencionales relevantes de las relaciones internacionales. Este último no es la superpotencia de la entonces Guerra Fría, pero sigue teniendo un poder regional de primer nivel. Es tiempo que Putin evalúe su persistencia de sostener a Al-Assad, a estas alturas totalmente desprestigiado y debilitado en el frente interno. La alianza podría salir más cara para Moscú, que ha sido cauto frente al reciente ataque de Washington al solamente declarar la condena de la agresión sin que reaccionara militarmente. Si miramos objetivamente la foto de Siria, confirmaremos que su futuro dependerá de actores exógenos, otra vez, EE.UU. y Rusia, principalmente, los que encontraron en el yihadismo la coartada perfecta para penetrar y buscar hegemonía en el Medio Oriente.

Los últimos sucesos en Siria a los que nos hemos referido persistentemente, es decir, el ataque del régimen de Bashar al-Assad a civiles mediante el uso de armas químicas, totalmente prohibidas por el derecho internacional, y la reacción estadounidense propinando un certero lanzamiento de misiles en una base militar, deben ser evaluados en su exacta dimensión jurídica internacional para conocer el tamaño de su reacción e impacto no solo jurídico sino desde la dinámica del poder y del equilibrio internacional. El ataque del dictador sirio que causó la muerte de 80 personas transgrede la Convención Internacional sobre Armas químicas de 1997, que proscribe terminantemente su uso en los conflictos armados. Hacerlo supone responsabilidad penal internacional para los autores del macabro suceso, que de todas maneras se va a producir en algún momento. Con lo anterior, la reacción militarizada de EE.UU. es unilateral e inconsulta, es decir, ha sido una decisión del Gobierno de Donald Trump que no ha contado con la aquiescencia del Consejo de Seguridad de la ONU, que conforme a la Carta de San Francisco de 1945, que es un tratado, posee la decisión del uso de la fuerza.

Un tercer presupuesto es que la ONU está legitimada para aplicar el uso de la fuerza únicamente en tres circunstancias y de modo excepcional: la legítima defensa, que no es el caso porque EE.UU. no ha sido atacado como sí sucedió en setiembre de 2001 cuando respondió al certero atentado que $\mathrm{Al}$ Qaeda le arremetió coludido con el régimen talibán de Afganistán; la seguridad colectiva, que se aplica en casos como el de Siria, eso es verdad, pero siempre por acción colectiva y nunca jamás unilateral, por lo que técnicamente la acción aérea de Washin- 
gton está al margen del derecho internacional; y ante el incumplimiento de las sentencias de la Corte Internacional de Justicia, el órgano judicial de la ONU, por parte de algún Estado miembro del foro planetario, que tampoco es el caso que comentamos, porque hasta ahora ningún Estado miembro de la ONU ha osado declararse en rebeldía a los fallos de la Corte. Esta es la exacta dimensión jurídico-política del actual escenario en Siria. Pero en nuestro análisis, que desde el comienzo es desde el derecho internacional y las relaciones internacionales teniendo como elementos del análisis los procesos convencionales y los no convencionales, veamos ahora una óptica desde las relaciones internacionales a la que debemos volver casi por imperativo del análisis preliminar de este ensayo. Hasta el final de la Guerra Fría — caída del muro de Berlín, 1989 (en el Perú era casi el final de la década perdida por el desastre económico de aquel entonces y el impacto letal del terrorismo)—, el escenario del poder internacional correspondía a EE.UU. y a la entonces Unión Soviética, luego disuelta, manteniendo poder regional Rusia, la mayor república soviética (fueron 17).

Dado que en el sistema internacional todo es cíclico, ahora la concentración del poder mundial corresponde a EE.UU. y a China. Rusia, entonces, con todos sus méritos militares a que nos hemos referido, ha sido desplazada por el gigante asiático que ha adquirido una hegemonía sin precedentes en el campo económico, tanto que a Washington ha alertado sobremanera su nivel de influencia en espacios territoriales que otrora fueron de indiscutible influencia estadounidense — nuestra América Latina, que ahora se ha expandido a otros continentes, es el mejor ejemplo, al haber sido atraída por el denominado bloque del BRICS que agrupa a China, Rusia, India y Sudáfrica y con ellos Brasil, el gigante sudamericano-.

Lo anterior explica la enorme expectativa del encuentro del presidente Donald Trump con su homólogo chino Xi Jinping, cuyos resultados se siguen manejando discretamente. No se crea que esta idea es óbice para suponer de qué hablaron en la reunión que sostuvieron en la residencia del magnate presidente, en Florida, Estados Unidos. La Casa Blanca nunca jamás ocultó el agudo asunto de Corea del Norte, que no cesa sus ejercicios nucleares. No perdamos de vista el realismo político, es decir, China valorará las circunstancias para no romper con Pyongyang, pero tampoco lo hará con Washington, en cuya economía Beijing ha penetrado sin detención. Trump seguirá buscando presionar a Jinping, pero así no funcionará la estrategia con los chinos. El gobernante asiático es más fuerte en el frente interno de su país que Trump dentro del suyo, dada la crisis que afronta por el asunto de la conexión rusa que sigue investigando un fiscal ad hoc que podría terminar por ponerlo en aprietos. El encuentro entre los mandatarios estadounidense y chino y que todos vimos el pasado 6 de abril de 2017, entonces, no es la foto de un nuevo mundo bipolar sino de uno unimultipolar, pues además de China, hay otros Estados relevantes en el globo que ya negocian directamente con EE.UU. 


\section{LA AMENAZA DE COREA DEL NORTE COMO ACTOR CONVENCIONAL}

La presión de Donald Trump sobre Xi Jinping tiene sus límites. Es verdad que la amenaza nuclear de Corea del Norte constituye un dolor de cabeza para Washington, pero ese es un problema que no lo va a solucionar China.

Hasta el papa Francisco ha sido muy claro. La pretendida disuasión nuclear que fuera el arma más efectiva de los Estados poderosos durante la Guerra Fría (1945-1989), etapa que siguió a la Segunda Guerra Mundial y que se caracterizó más bien por la prevalencia de la amenaza y el espionaje sin que se produjeran enfrentamientos armados de carácter planetario y en modo predominante, ya no resulta ser el método más adecuado para lograr los objetivos estratégicos de los Estados. Las razones que aduce el papa son importantes: el terrorismo, los conflictos asimétricos, la seguridad informática, los problemas ambientales y la pobreza. Todo lo anterior es verdad, pero también lo es que el hombre es el constructor de sus propias amenazas.

La teoría de la involución humana encuentra en la amenaza nuclear una eventual justificación en el futuro de la humanidad. El avance científico ha tenido en las últimas décadas un desarrollo explosivo. Esa realidad llevó a que los Estados decidieran la firma de un sinnúmero de acuerdos internacionales que reflejaran el deseo de la erradicación de esta arma mortífera. La comunidad internacional es consciente de las consecuencias que produjeron los estallidos atómicos en Hiroshima y Nagasaki en agosto de 1945, que precipitaron, por sus execrables resultados, el final de la Segunda Guerra Mundial. Nadie los quiere en la actualidad.

El papa busca minimizarlos y estratégicamente — lleno de buena fe- aún no sabe si es lo mejor. Lo que sí sabe el primer pontífice americano, y no puede evadir, es que los países que podrían contar con arsenal nuclear o con capacidad para elaborarlos, como podría ser el caso de Corea del Norte o de Irán, son una verdadera caja de pandora. La disuasión nuclear quizás no sirva de mucho para acabar con el Estado Islámico - y no lo digo por una ausencia de proporcionalidad - ni con Corea del Norte, pero está claro que como letal mecanismo disuasivo, su sola tenencia constituye un arma estratégica

El régimen de Corea del Norte es una incertidumbre completa. No porque no se tenga certeza de cómo es la vida intraestatal en Pyongyang sino porque la reacción del gobernante Kim Jong-un es impredecible, sobre todo a la luz de la muerte de su hermano Kim Jong-nam en Malasia el 13 de febrero de este año, lo que ha desatado un estado de tensión regional donde la regla es la amenaza. En efecto, el asesinato de su hermanastro ha derivado en una crisis de rehenes bilateral sin precedentes. Nadie lo podría creer sobre todo porque Malasia es de los pocos países con los que Pyongyang ha mantenido un nivel de relaciones, diríamos, aceptable. 
Con el agravamiento de la crisis por el asesinato, los malasios en territorio norcoreano tendrán temporalmente prohibida la salida hasta que la situación sea resuelta. La finalidad, añadía, era proteger la seguridad de sus ciudadanos y diplomáticos en el país del sudeste asiático.

La retención de nacionales está prohibida por la Convención de Viena sobre Relaciones Diplomáticas, firmada por ambos países, y por la Declaración de Derechos Humanos de la ONU, que Pyongyang no ha secundado. Medida poco inteligente de Norcorea, pues en este país apenas viven once malasios, entre personal diplomático y familiares, mientras que los norcoreanos en Malasia llegan al millar, no solo diplomáticos sino trabajadores que Pyongyang manda al exterior para que envíen las necesitadas divisas a un régimen estrangulado por las sanciones internacionales. Hasta antes del funesto suceso en el aeropuerto de Kuala Lumpur, donde dos mujeres interceptaron a Jong-nam, ambos países compartían una política de entrada sin visados que incrementó la llegada de norcoreanos a Malasia. Con las medidas de Pyongyang, la respuesta de Kuala Lumpur ha sido cancelar esa política.

Pero mirando el tablero de esa región más ensanchado, lo primero que debe tenerse presente es que las Coreas mantienen desde 1953 un armisticio que, de acuerdo con las reglas del derecho internacional, no es un acuerdo ni un tratado de paz, sino únicamente un cese de las hostilidades entre las partes en conflicto. Desde esa época en que quedaron divididas políticamente mantienen una zona desmilitarizada de 4 kilómetros alrededor del paralelo $38^{\circ}$ en el territorio de la península que las define geográficamente, conservando cada una un statu quo bastante singular, aceptando por más de 60 años un uti possidetis de iure, es decir, donde cada uno retiene para sí el mismo espacio territorial que poseía al momento del armisticio.

En segundo lugar, Corea del Norte mantiene un régimen cerrado y totalitario donde el poder es monopolio de una casta familiar — hoy lo detenta Kim Jong-un-, que solo sabe actuar con la intimidación y sobre el que sus opositores han insinuado que tendría que ver con la muerte de su hermano. En tercer lugar, el régimen totalitario norcoreano no tiene el potencial militar ni nuclear del que alardea, aunque sí puede provocar un escenario más complejo y de impacto a escala si acaso una decisión irresponsable y fanática de su líder desata en la región un escenario inmanejable. La actitud permanente de Pyongyang ha sido la de acusar a Seúl de liderar una propaganda contra Norcorea buscando poner en alerta a la comunidad internacional.

En cuanto a China, su aliado tácito en la región, desde que ha llegado al poder Donald Trump en Estados Unidos, está claro que Beijing, que no quiere tener conflictos con Washington, ha mostrado un giro atípico que resulta interesante analizar, sin que el propio Washington desconozca la existencia de la aparición de un nuevo equilibrio del poder tal como hubo en el sistema internacional del pasado. ${ }^{7}$ En efecto, el denominado gigante asiático, que

Hans J. Morgenthau, La lucha por el poder y por la paz, traducción de Francisco Cuevas Cancino y un grupo de estudiantes del Centro de Estudios Internacionales (Buenos Aires: Editorial Sudamericana, 1963), 460-464. 
ya ha mostrado restricciones en el comercio hacia y desde Pyongyang, la capital norcoreana, impactando básicamente en el comercio bilateral de materias primas, sabe que lo hace porque quiere conquistar el mundo, lo cual hace de Corea del Norte un régimen vulnerable. Está claro que China no quiere pelearse con la comunidad internacional expresada en la ONU, que, sin inmutarse, a través del Consejo de Seguridad, oportunamente ha emitido sanciones al país. La situación de hoy, entonces, incorpora una posición distante entre Pekín y Pyongyang, quizás la primera claramente frontal con las actitudes asumidas por el nefasto régimen de Kim Jong-un.

Para nadie es un secreto que China, país con un aparato logístico extraordinario, ha venido apoyando con políticas asistencialistas a Corea del Norte desde los tiempos en que se inició el referido armisticio. Desde que EE.UU. decidió concentrarse en el Medio Oriente y específicamente en el Estado Islámico, promoviendo la ya referida coalición de más de 40 países que lidera con el objeto de acabarlo, China no había hecho visibles sus adhesiones. Los chinos están preocupados por asegurar su liderazgo en el comercio internacional planetario y no están dispuestos a pelearse con Occidente. Esa es la verdad.

En cuanto a Corea del Sur, este país ha venido aplicando sanciones para Pyongyang, vetando un conjunto de transacciones económicas con la participación de norcoreanos, e incluso oportunamente estableció que las embarcaciones que por alguna razón ingresen en sus aguas también serán sancionadas. El endurecimiento de Seúl ha seguido a las amenazas del Gobierno del tirano gobernante norcoreano. Suma que a la cancillería surcoreana no se le quita la idea de que altos funcionarios de Pyongyang estarían comprometidos con programas nucleares y misiles llegados de Rusia.

La realidad de todo este asunto es que al régimen de Pyongyang le irrita que permanentemente Washington y Seúl realicen ejercicios militares conjuntos. En el análisis del referido tablero de la región, desde afuera, los Estados poderosos de esa región — China y Rusiamiran con discreción lo que allí sucede, dejando que sean EE.UU. y Seúl los que sigan presionando al Gobierno colapsado y anacrónico de Pyongyang. Kim Jong-un, tras la muerte de su hermano, se ha dedicado a amenazar a los Estados de la región. Está claro que Jong-un no pudo encontrar mejor pretexto y que sigue siendo, por cierto, todo un misterio, para hacer visible el protagonismo que tanto le importa a fin de mantener su liderazgo en el frente interno de un Estado con régimen cerrado y colapsado.

Corea del Norte es todo un enigma. Impenetrable, en realidad poco se sabe de este país gobernado por una dinastía — Kim- desde hace 70 años. El éxito para mantener la vigencia del régimen es la imposición del culto al líder como política de Estado y el miedo y las ejecuciones como regla, o con mejor suerte para los disidentes, acabar sus vidas en los campos de concentración y trabajos forzados. Este año se ha celebrado el $105^{\circ}$ aniversario del nacimiento 
de Kim Il-sung, que iniciara la historia de una vil dinastía de dictadores —abuelo, padre e hijo- y que a su muerte, en 1994, fuera declarado Presidente Eterno. El Gobierno comunista conmociona al mundo ante la eventualidad de una reacción bélica por la presencia naval estadounidense en las costas de la península buscando disuadir a los norcoreanos, y que por supuesto las pocas agencias de noticias del régimen se han encargado de ningunear.

Así las cosas, con 25 millones de habitantes que han sido obligados a solamente vestir de oscuro, Pyongyang - capital norcoreana - se ha convertido en el mayor dolor de cabeza para la comunidad internacional. Sobre este país y su actual líder — Kim Jong-un—, solo se puede especular acerca de su reacción militar. En los últimos años ha desarrollado la política exterior de la amenaza, no solo a Corea del Sur, su mayor enemigo, sino a los aliados de Seúl, principalmente Washington.

Los lanzamientos de misiles al mar en señal de ejercicios nucleares, a pesar de la condena mundial, han logrado su cometido de generar alarma en el globo. Preocupa y mucho que el presidente Donald Trump haya dicho que podrían reaccionar ante Pyongyang - por sus recientes decisiones en Siria y Afganistán ya no se sabe qué pueda resolver- y preocupa también que Jung-un anuncie que no se quedaría de brazos cruzados sin dar una lección a Occidente, sobre todo cuando se especula acerca de su real poderío nuclear.

\section{LA SOCIEDAD INTERNACIONAL DE LA BARBARIE}

Lo cierto de toda la reflexión que hemos abordado es que estamos volviendo a la sociedad internacional de la barbarie. En el comienzo de la civilización, el conflicto marcó a la vida humana por el dominio. Evolucionamos hacia una comunidad planetaria de paz después de la Segunda Guerra Mundial, pero ahora, con la aparición del terrorismo internacional, estamos siendo impactados por un fenómeno de dimensiones brutales.

Desde que apareció el Estado Islámico en el 2014, el mundo convive con el terror, que se muestra más sanguinario que nunca. Grupos humanos son decapitados en masa, y esos macabros episodios son colgados en Internet para aterrorizar al mundo. Los ataques suicidas contra poblaciones indefensas, como acaba de suceder en Berlín o Zurich, revelan que el terrorismo no tiene límites. La idea es causar terror y pánico colectivos, y la mejor forma de hacerlo es matando personas indiscriminadamente.

Lo que sucede es que el terrorismo encuentra en la guerra en Siria el escenario ideal para lograr sus objetivos. Si ellos quieren formar un califato, debe haber desestabilización en el país, y eso es lo que exactamente está sucediendo. Ver cómo las fuerzas del régimen de Bashar al-Assad, para recuperar la importante ciudad de Alepo, realizan, con el apoyo de Rusia e Irán, una completa carnicería humana contra poblaciones indefensas so pretexto de eliminar a los rebeldes es precisamente lo que el Estado Islámico como tercer actor está buscando. 
Lamentablemente sí, EE.UU. y Rusia quieren tener el control de Siria. A estas alturas del año - hemos llegado a la mitad — no se han podido poner de acuerdo para vencerlo, porque mientras Washington quiere derrocar al dictador sirio mostrando su apoyo a los rebeldes al régimen, los rusos se han pegado a Al-Assad y están sellando su alianza estratégica.

El rol de la coalición internacional está viciado por concentrarse en el asunto del destino político de Siria. La coalición ha caído en el juego del Estado Islámico, que sabe replegarse a pesar de las bajas que ha tenido. Veamos cómo ni Rusia ni EE.UU. han sido capaces de ponerse de acuerdo para derrotarlo. La rivalidad entre ambos países los ha hecho perder perspectiva. Hasta ahora ha sido Rusia la que se ha empoderado.

Lo que buscan EE.UU. y Rusia en Siria o en Irak es lo que quiere toda potencia: afirmar su marco de influencia geopolítica y económica. Mientras Washington viene desde hace más de 35 años queriendo ampliar y copar su marco de alianzas — comenzó con Egipto hace más de 30 años con el régimen de $\mathrm{H}$. Mubarak, luego con Jordania que no demandó mayor esfuerzo, la rica y poderosa petrolera Arabia Saudí haciéndose de la vista gorda sobre las violaciones de derechos humanos que se le han imputado al régimen, la decisión de intervenir en Irak para sacar al sunita Sadam Hussein e instalar un Gobierno a la medida de EE.UU y hasta establecer hábilmente una alianza estratégica con Irán por el programa nuclear con el objetivo de neutralizarlo dada su dimensión de verdadera fuerza chiita en la región-, los rusos aprendieron de la experiencia del fracaso en Afganistán, del que tuvieron que retirarse en los años ochenta.

El objetivo ruso no se detiene. Reiteremos que los rusos menosprecian las reglas del derecho internacional e imponen su poder regional - lo hicieron en Ucrania anexando ilegalmente Crimea-, y colaboran con Bashar al-Assad no solamente porque quieren mantener la única base naval, Tartus, con que cuentan en el Medio Oriente, sino porque a Putin le preocupa que EE.UU. termine de controlar toda esa inmensa región.

Estamos viviendo acciones internacionales que solamente están fundadas en intereses, y lamentablemente siempre ha sido así. En la historia de la sociedad internacional las movilizaciones de los Estados y otros actores han sido básicamente por recursos. La hegemonía en ese sentido no ha cambiado. Por eso, lo que estoy tratando de expresar en este ensayo en otras palabras, es lo que dice la ciencia de las relaciones internacionales, que lo explica todo pues es la ciencia que estudia precisamente los fenómenos conflictuales que suceden en el mundo, pero siempre mirando desde el fondo del asunto, nunca solamente el problema por fuera.

Los asesinatos perpetrados pueden ayudarnos a comprender el asunto. Veamos el vector Turquía. Es evidente que este país es pieza clave en todo este proceso conflictual que se vive en el Medio Oriente. Las cuotas de los migrantes que salieron de Siria hacia Europa y que el 
Viejo Continente no ha querido más cobijar a pesar de los principios del derecho internacional de los refugiados y hasta del derecho internacional humanitario que establecen compromisos de los Estados, está claro que Turquía terminó asumiéndolas como activos. Hacerlo le ha costado mucho al Gobierno turco de Recep Tayyip Erdogan, que busca congraciarse con Europa a la que intenta ingresar a como dé lugar. Pero téngase presente que el régimen turco no ha podido revertir la fragilidad que atraviesa debido a varios frentes internos altamente sensibles, es decir, en Turquía coexisten fuerzas anarquistas y contestarias que quieren acabar con el Gobierno de Erdogan, y súmense a ello las aspiraciones independentistas de los kurdos. Está claro que el policía que mató al embajador ruso revela que esas fuerzas que buscaron derrocarlo por un golpe de Estado frustrado no quieren que se afirme la relación bilateral con Rusia, que comenzaba a salir de su etapa crítica. Ahora retrocederá y, lo que es peor, Putin manejara a su antojo a Tayyip Erdogan.

La ONU, en la era A. Guterres que ya lleva medio año al frente de la organización internacional, es verdad que se pronuncia, pero también lo es que debe tener una participación más activa en el conflicto. Debe liderarlo para darle legitimidad internacional al proceso en esa región. Todavía tendremos que seguir asistiendo al conflicto no convencional del terrorismo internacional como la mayor amenaza porque no ha sido abordado mirando el interés de todo el planeta sino de muy pocos actores.

Washington de Donald Trump es sumamente pragmático. Le ha puesto la puntería a 10 compañías aéreas que vuelan desde el Medio Oriente o el norte de África hacia EE.UU. La medida es por tiempo indefinido e impide que los pasajeros pudieran llevar computadoras o tabletas, o en general, grandes aparatos electrónicos, en la cabina de los aviones. Solo serán permitidos apagados y en las bodegas de las aeronaves. Los ataques terroristas hace rato han superado los controles tradicionales en los aeropuertos, y esa es la razón de peso que ha llevado a la adopción de este tipo de decisiones por parte del Gobierno de Donald Trump, que no quiere sorpresas.

Está claro que nada de lo que decide el Gobierno estadounidense se hace sin contar con un reporte previo de su sistema de inteligencia. Se nota que la CIA, por encargo del presidente en esta nueva etapa, está realizando una inversión extraordinaria en las tareas de neutralización de los actos terroristas. Tiene lógica, pues gran parte de quienes votaron para darle el triunfo a Trump lo hicieron porque confían en que el presidente los sacará del trauma del 11 de setiembre de 2001, fecha en que EE.UU. perdió su calidad de Estado invulnerable a manos de Al Qaeda, que en ese momento, con Osama Bin Laden, se había coludido con el entonces régimen talibán en Afganistán para atacar Norteamérica y cambiar los paradigmas del sistema internacional. Precisamente, los mayores temores en la últimas horas estarían centrados en el propio Al Qaeda, organización terrorista que mermada luego del abatimiento de Bin Laden en Islamabad, Pakistán (2011), habría recobrado espacios desarrollando tecnologías informá- 
ticas tan sofisticadas, que los sistemas de seguridad no podrían prever su detección. Todo lo anterior afecta, y mucho, a los países africanos y a los del Medio Oriente, que siguen siendo estereotipos de amenaza. Injusto, pero real.

\section{DONALD TRUMP COMO ACTOR DE LAS RELACIONES INTERNACIONALES}

Al cuestionado presidente Donald Trump, nacido en la emblemática ciudad de Nueva York, a los 70 años de edad en que se ha convertido en el cuadragésimo quinto presidente de la historia de los Estados Unidos de América, deben tocarle tiempos más complejos si acaso no cambia algunos de sus formatos anteriores, sobre todo los que tenía cuando candidato a la presidencia del su país.

En el frente interno de su país, ha mandado a la sepultura política a un grueso de políticos del tradicional bipartidismo estadounidense encarnado por demócratas y republicanos. Se presentó en la campaña en modo irreverente. No cambió para nada su excéntrico estilo que muchos criticaron y al final esa conducta atípica caló profundo en un amplísimo sector de ciudadanos, preferentemente blancos de clase media sin grados ni títulos y de los sectores rurales del país, todos ellos olvidados por largo trecho en el itinerario de la larga vida nacional del hegemón, y por esa llave maestra que Trump interpretó como nadie, fue ungido presidente el 20 de enero de 2017.

Trump es un completo fenómeno político de carácter atípico al que todos subestimaron hasta el cansancio. En adelante, el magnate lidia para acostumbrarse a asimilar que su vida que ya no es la misma. Su alta figura como presidente de la Nación más poderosa de la tierra acumula para él una enorme responsabilidad. Sus primeras palabras, luego de conocer que había pasado el mínimo de los 270 delegados o electores exigidos para ganar la presidencia del total de 538 que comprende el Colegio Electoral, fue de integración y deliberadamente conciliador. Trump sabía que su primera prueba de fuego paradójicamente debía ser apagar la ola de especulaciones que se habían prendido al advertirse la inminencia de su victoria política sobre Clinton. Lo hizo y progresivamente la Bolsa de Valores de Tokio, por ejemplo, que se había ido cuesta abajo, fue retomando su nivel discrecional esperado y hasta el alicaído peso mexicano, desplomado por horas, recobró su posición de siempre, por cierto nunca totalmente alentador.

Esa misma actitud la repitió en el encuentro que sostuvo con Obama en la Casa Blanca, a donde acudió invitado por el entonces saliente mandatario. Trump no está escuchando a sus asesores, y ese no es un buen signo. Su figura de controvertido candidato que llevó a la polarización del país sería insostenible en la presidencia, y eso lo tiene muy claro, pues nadie -léase el poder real— se lo podría permitir, como tampoco nadie se lo pudo permitir a algunos otros presidentes que en la historia estadounidense terminaron muy mal. 
No digo que vaya a dejar de lado las promesas electorales que lanzó por doquier durante la campaña, pero sí que las va a priorizar y hasta matizar, y eso es exactamente lo que viene haciendo en medio año de gobierno. Por ejemplo, en lo que corresponde a la agenda internacional del país que ya ha encontrado y que es muy diversa, la historia de la diplomacia estadounidense ha enseñado que en la visión externa del país los cambios que pudiera haber en el camino no suelen ser radicales sino progresivos. La calidad de Estado poderoso es una circunstancia que supera a los propios presidentes de turno. Trump actúa hasta ahora, a mi juicio, de menos a más, con el realismo político que el tamaño del nuevo peso que lleva sobre sus hombros le va a demandar en adelante.

La teoría de la interdependencia es cada vez más importante y necesaria en el mundo de hoy, donde todo se encuentra entrelazado por la globalización. Ser presidente de los EE.UU. lleva a Trump a medirse con Rusia y por lo menos a no mostrarse tan adicto al presidente Vladimir Putin. El asunto del cambio climático, del que acaba de alejarse, produce una completa incertidumbre internacional.

Trump no puede ir contra el mundo, esa es una exigencia planetaria que acaba de pisotear. Su tarea de asegurar una sociedad de paz para todos los estadounidenses, los mismos que siguen soportando los estragos del trauma colectivo por el ataque terrorista de 2001, es su mayor obligación.

No veo a Trump - aunque ya no se sabe- estropeando el acuerdo sobre un programa nuclear para Irán, pero sí realizando ajustes en relación a la estrategia en Irak y en Siria con el objeto de derrotar al Estado Islámico. No veo a Trump volviendo a congelar la relación restablecida con Cuba, que tiene carácter inexorable e irreversible, pero sí ajustando a Venezuela, a la que, sin involucrarse directamente por medios que no sean sino estrictamente sanciones económicas, buscará liberar del régimen dictatorial de Nicolás Maduro. Trump sabe que América Latina es un continente en crecimiento; es verdad que crece menos, pero, al fin y al cabo, crece. Trump sabe que aquí la interdependencia es una realidad indubitable. Sabe que los países del BRICS — China, Rusia, India y Sudáfrica — quieren a nuestra región por nuestros recursos —entrando por Brasil, también miembro de ese bloque emergente- y no les dará tregua en ese propósito. Trump trabaja para ganarse a la otra mitad de sus conciudadanos que no votaron por él al considerarlo un antisistema. No es un buen inicio el que está enfrentando, sobre todo cuando hay sectores que piden su renuncia. Estados Unidos, ahora más que nunca, no va a renunciar a su denominada "grandeza americana" inscrita en el imaginario colectivo de su pueblo y que Donald Trump ha sabido interpretar. Esa es su tarea. Es probable que pida pronta audiencia a Henry Kissinger, el gurú de la diplomacia estadounidense, y también que este le inspire una fórmula para que haciéndose progresivamente estadista, el nuevo presidente lleve adelante la responsabilidad de mantener a su país en la calidad de superpotencia. Trump sabe que Estados Unidos no puede perder esa condición y 
podría recurrir al pretexto como palanca para relievar esa condición, y lo hará en una sociedad internacional anárquica por naturaleza, pues "un Estado utilizará la guerra para lograr sus objetivos si, después de evaluar las posibilidades de éxito, considera más importantes esas metas que las bondades de la paz,"

El asunto de Irán es para Donald Trump el más importante de todos los que pueda haber en el Medio Oriente. La fijación del presidente estadounidense está en que Irán llegue a contar, y en poco tiempo, con un arma nuclear de tal manera que se encuentre en la posibilidad de cambiar la correlación de fuerzas en ese convulso espacio geográfico. Su inquietud la desnudó en el marco de la reunión sostenida con Benjamín Netanyahu, primer ministro de Israel, en la Casa Blanca. Trump ha criticado abiertamente el acuerdo del programa nuclear para Teherán que firmaron los países miembros del Consejo de Seguridad más Alemania con la República Islámica de Irán. Aunque lo ha denostado, no creo que vaya a arruinarlo.

Hemos dicho en reiteradas ocasiones que Irán no es un país cualquiera. De hecho cuenta con la fuerza de equilibrio o contrapeso más importante en esa región, pues de las naciones islámicas, realmente ha sido la única que jamás ha ocultado su odio hacia Israel hasta llegar a amenazarlo con la extinción del pueblo judío. Todavía está por verse la reacción que pueda mostrar Teherán a una eventual renegociación que se le ocurra a Trump. El presidente iraní, Hassan Rohani, ha sido claro al asegurar que ni Trump ni nadie va a modificar el acuerdo alcanzado. Se trata, entonces, de un discurso retador. Irán ha salido de las sanciones que le fueron impuestas por Washington luego del mentado acuerdo. El mayor país chiita ha sentido los estragos de la sanción, eso es indudable, pero me temo que ante la posibilidad de que Trump patee el tablero, va a endurecer su posición hacia EE.UU. e Israel y hasta sobre sus demás aliados estratégicos, como es el caso de Arabia Saudí, el mayor enemigo musulmán de Irán en esa región, con lo cual el escenario de tensión y conflicto en el Medio Oriente podría verse ensanchado

Donald Trump parecía que había reconsiderado su posición sobre la OTAN —la ha criticado de obsoleta - pero no es cierto, la ha seguido vapuleando sin cuartel aun cuando sabe que ante la inminencia de un conflicto a escala con Corea del Norte la va a necesitar. La Organización del Tratado del Atlántico Norte (OTAN), cuyo origen lo hallamos en la firma del Tratado de Washington de 1949, en que fueron diez países de ambos lados del Atlántico (Bélgica, Canadá, Dinamarca, Estados Unidos, Francia, Islandia, Italia, Luxemburgo, Noruega, Países Bajos, Portugal y Reino Unido) los que decidieron la defensa mutua en caso se produjera una agresión armada contra cualquiera de ellos. Era evidente que su creación había llamado la atención de la entonces Unión Soviética, que buscó promover un contrapeso a la OTAN. Moscú al verla más bien como una amenaza, decididamente creó un espacio

8 Kenneth N. Waltz, El hombre, el Estado y la guerra (Buenos Aires: Editorial Nova, 1959), 173. 
geopolítico de influencia entre los países que se hallaban en la condición de periféricos de la U.R.S.S., y plasmó en 1955 el denominado Pacto de Varsovia. El presidente estadounidense no puede perder de vista que la OTAN se hizo sobre la base del artículo $51^{\circ}$ (Capítulo VII) de la Carta de Naciones Unidas, que reconoce el derecho inmanente de legítima defensa, individual o colectiva, en caso de ataque armado. Será un grave error no atenderla como corresponde.

Hoy, la amenaza más importante para Estados Unidos y en general para el mundo entero es el terrorismo internacional, un problema que sí resulta una prioridad para Trump, y lo venimos diciendo a lo largo de este ensayo. Durante la campaña, Trump criticó a la OTAN, de la que dijo incluso que mantenía sus cuentas con déficit por la falta de pagos de sus demás miembros. La seguridad internacional no se puede soslayar — también están China y Corea del Norte como preocupaciones-, y Trump parece entender el rol de la OTAN.

El presidente de EE.UU, Donald Trump, no se da por vencido, y, lo que es más grave, todo lo soslaya. Su política exterior para impedir que los refugiados ingresen en el país, que vociferó a los cuatro vientos durante toda la campaña para llegar a la Casa Blanca, precisamente en el país que dice llamarse de todas las sangres, fue neutralizada por dos magistrados estadounidenses.

Parecía que Trump había perdido desde el comienzo y sintió que la medida jurisdiccional ponía fin a su decisión política. Fiel a su carácter y estilo, donde la derrota pareciera no existir, ha firmado una nueva orden ejecutiva que matiza el impedimento de ingreso de personas procedentes de Irán, Somalia, Yemen, Libia, Siria y Sudán, países de mayoría musulmana. Sus medidas colisionan con aquellos islámicos que tengan la tarjeta de residentes permanentes — green card—, que permite a los extranjeros trabajar en el país. Sí, en cambio, quedan desprotegidas las minorías religiosas cristianas. Otra de las medidas permite el ingreso de iraquíes en EE.UU., pero al mismo tiempo acelera la política de expulsiones. Podrán permanecer en suelo estadounidense aquellos que lograron asilo, y retira la prohibición indefinida de ingreso de los sirios.

Finalmente, todos aquellos que tengan doble nacionalidad que sea distinta a los referidos países vetados, también podrán ingresar en el país. La insistente estrategia de Trump pasa porque las nuevas medidas solo tienen carácter temporal. Así puestas, evita la avalancha de críticas y de presiones en el frente interno que a la larga estaban minando su gestión desde el arranque. Pero Trump no se quedará de brazos cruzados. Estoy persuadido que de todas maneras expulsará o deportará muchas gente en el camino. Eso será casi del tamaño de impedir que ingresen extranjeros en el país. Frena las medidas impuestas por la justicia de EE.UU., buscando no mostrarse jamás como vencido políticamente. En esto será tiempo al tiempo. 


\section{LAS NACIONES UNIDAS DE ANTONIO GUTERRES}

En este orden mundial en movimiento, Antonio Guterres, que salió airoso como el favorito para ocupar el alto cargo de secretario general de la Organización de las Naciones Unidas - 5 votaciones informales y una formal en el seno del Consejo de Seguridad - , fue finalmente elegido por la Asamblea General de la ONU desde el 1 de enero de 2017, por cinco años, hasta el 31 de diciembre de 2021.

El prestigioso político y diplomático nacido en Lisboa en 1949 aún no cobra el protagonismo que se le requiere. Los diez años que ha dedicado como Alto Comisionado de las Naciones Unidas Para los Refugiados - ACNUR (2005-2015) le permitieron ingresar a los asuntos de fondo de uno de los temas más complejos que viene enfrentando la ONU y, en consecuencia, la humanidad, como es la problemática de los referidos refugiados y desplazados que llegan a más de 65 millones, es decir, de aquellos que huyen de sus lugares de origen ante la inminencia del peligro de sus vidas o cruzando las fronteras para solventarse seguros. La ONU de la era Guterres deberá enfrentar retos importantes como el fenómeno de la migración internacional, que ha venido a configurar un nuevo escenario en el globo por los efectos que ella produce, como la crisis humanitaria donde se calcula en más de 130 millones de personas las que requieren atención por parte de la comunidad internacional.

Junto a lo anterior, Guterres deberá mostrar una participación más visible y protagonista de la ONU en el conflicto de Siria, que hasta ahora aparece nebuloso. La ONU es la depositaria de la paz y la tranquilidad internacionales por las que debe velar permanentemente, conforme lo establecido en la Carta de San Francisco de 1945.

Desde esa perspectiva, la ONU deberá abordar más decididamente el asunto del terrorismo internacional, objeto de este ensayo, como fenómeno no convencional, sobre el cual se espera del foro una reacción con mayor eficacia, mostrando, por ejemplo, mayor protagonismo que la denominada coalición internacional contra el Estado Islámico de Irak y el Levante, que encabeza EE.UU. La incorporación del Estado de Palestina como miembro pleno de la ONU, una aspiración a la que se oponen notoriamente Israel y Washington, será otro de los retos que deberá solventar Guterres en este año, dado que resulta insostenible que en pleno siglo XXI no se pueda permitir al pueblo del desaparecido Yasser Arafat el estatus que tienen los otros 193 Estados Parte de la organización; además, no deberá temblarle la mano para no solamente condenar los innumerables casos de denuncia por abuso sexual de cascos azules en operaciones de paz en África, sino que deberá hacer visible su intención de promover la acción penal contra quienes resulten responsables.

Su prestigio hasta ahora ha jugado a su favor y estará como nunca antes. Desde enero de este año, está en la mira de la comunidad planetaria. Se acaban de cumplir 6 años de la guerra en Siria, convertido en el mayor conflicto en el Medio Oriente en mucho tiempo, despla- 
zando por sus atroces resultados al de larga data palestino-israelí. Los tres actores visibles en la guerra son: el régimen dictatorial de Bashar al-Assad que, apoyado por Rusia e Irán, no ha podido ser derrocado; los rebeldes que cuentan con el aval de EE.UU., que jamás ha ocultado su propósito de acabar con Al-Assad; y el terrorismo del Estado Islámico (EI), que, siempre buscando jamás pasar desapercibido, es el autor del atentado en Damasco, en el que han perecido 30 inocentes.

El alcance de las resoluciones de la ONU no debe ser un motivo para justificar el poder algunas veces desvanecido del secretario general de la ONU. Por regla general, las resoluciones de la ONU solo tienen carácter de recomendación, es decir, no son obligatorias o imperativas. Una razón de fondo sustantiva es que la ONU es un foro político de Estados donde sus miembros - 193 - se encuentran en una relación horizontal o plana, es decir, sin jerarquías, donde ninguno es más importante que el otro. Ahora bien, las resoluciones emanan de cualquiera de los 6 órganos de la ONU —-Asamblea General, CS, Corte Internacional de Justicia, Secretaría General, etc.- y pueden versar sobre admisión de nuevos Estados como miembros de la ONU, determinación del presupuesto, elección de miembros no permanentes del CS, establecimiento de misiones de mantenimiento de paz, textos de instrumentos multilaterales, declaraciones políticas, cuestiones de procedimiento, y hasta sanciones económicas. No perdamos de vista que la naturaleza o razón de ser de una resolución determina si tiene carácter obligatorio para los Estados o no.

Frente a todo lo anterior, en la calidad de resoluciones obligatorias, por excepción, se encuentran las que son aprobadas por el Consejo de Seguridad en virtud del Capítulo VII de la Carta de la ONU de 1945, de conformidad con el artículo 25 -Capítulo V- también de la propia Carta de San Francisco. En algunos casos, y esto es lo diferenciador, el propio Consejo puede recurrir a la imposición de sanciones que supongan el uso de la fuerza con el único objeto de mantener o restablecer la paz y la seguridad internacionales.

La guerra de Siria no sería la primera manifestación de una ausencia de eficacia por parte de la ONU en su calidad imperativa. Cabría, entonces, preguntar: ¿cuál es su papel?,9 o es que seguirá siendo un foro importante pero atenuado por el verdadero poder que incluso sostiene su vigencia. A la fecha, llegarían los muertos por la guerra a los $450 \mathrm{mil}$ y a 1,5 millones los heridos. Siria es un país en ruinas — más del $70 \%$ de su infraestructura ha sido destruida-, incluidos los recintos históricos de Palmira y Alepo. Esta devastación ha convertido a Siria en el país causal del mayor fenómeno migratorio del planeta, superando al que hubo por los estragos de la Segunda Guerra mundial y que originó la creación del Alto Comisionado de las Naciones Unidas para los Refugiados (ACNUR). En efecto, por lo menos 5 millones de sirios huyeron del país, mayoritariamente a los países vecinos, pero también

9 Raymond Aron, "Paz y guerra entre las naciones”, Revista de Occidente Bárbara de Braganza, 12 (1963): 647. 
a Europa, y unos 8 millones han debido dejar sus casas desplazándose por otros lugares del país buscando zonas seguras. La factura económica llega a los 170 mil millones de euros, devaluándose la libra siria en un $1000 \%$. El ejército sirio controla los espacios urbanos del país, aunque ya ha recuperado importantes espacios rurales que seguían en manos de los rebeldes y del Estado Islámico. A Rusia le ha ido mejor que a EE.UU. Su empoderamiento está determinando que las próximas negociaciones sobre el futuro de Siria, por primera vez, no serán en Ginebra sino en Kazajistán. En ese contexto, la ONU de la era Guterres debe mostrar la diferencia para hacer prevalecer la paz en una guerra en que hasta ahora todo ha colapsado. No habrá orden internacional sin liderazgo de la propia Naciones Unidas y, por supuesto, de su secretario general.

Pero volviendo al rol del presidente de la nación que comporta gran parte del destino del orden mundial, diremos que a pesar de todo el revés del presidente Trump, nadie le va a quitar la idea de que mantener la mejor de las relaciones con Vladimir Putin es lo mejor que le pueda suceder en estos momentos a la estrategia internacional de los EE.UU., sobre todo cuando tiene un frente interno bastante complejo. Durante la campaña llegó a decir que admiraba al presidente ruso y recientemente ha considerado la necesidad de moderar las opiniones que sostienen que el moscovita sea un asesino. Trump es consciente del importante poder regional de Rusia. La evidencia más inmediata ha sido que el régimen sirio de Bashar al-Assad —repito- ha recuperado espacios como Alepo dominados por los rebeldes y también por las porciones terroristas del Estado Islámico, gracias al poder militar mostrado en la zona por Moscú. Trump sabe que aliarse con Putin para combatir al Estado Islámico ha sido su mejor negocio en lo inmediato. El presidente magnate ha bajado sus decibeles de considerar a Putin como un fuera de serie, pero indirectamente lo defiende.

En el ya referido frente interno cuenta con una montaña de oposiciones en el aparato político para enfrentar a los terroristas, y desea contar con el mejor contexto internacional para las acciones que tiene pensadas llevar adelante. Pero Trump también quiere tener cerca a Rusia para luego jaquear a China, su mayor amenaza internacional por el extraordinario desarrollo alcanzado por el gigante asiático en los últimos años. Buscando accionar exactamente la estrategia inversa a la que acudió Richard Nixon en los años setenta, queriendo aliarse con China para restarle peso y gravitación a la entonces Unión Soviética, Trump, entonces, quiere asegurar el espacio hegemónico con que cuenta Washington desde hace más de un siglo en el sistema internacional. Putin, que las sabe todas, no lo contradice, y, en cambio, dice de Trump que es "un hombre muy brillante y talentoso". La táctica de palabras bonitas de ida y vuelta juega en las relaciones internacionales para resultados específicos. Nada más. 


\section{LA AMENAZA AL ORDEN MUNDIAL}

Pero, ¿qué es lo visible en las relaciones internacionales de hoy? El mundo se muestra cada vez más tensionado por donde se lo mire, y muchos creen que ello se debe al presidente estadounidense Donald Trump. Desde que ingresó en la Casa Blanca, sus órdenes ejecutivas han alborotado a la comunidad internacional, sedienta de paz y tranquilidad. Una de las más controversiales ha sido la de restringir el ingreso de personas procedentes de siete países musulmanes del Medio Oriente. Un despropósito total que ha generado protestas dentro y fuera del país, cuya exacerbación mayor podría reavivar la tesis del choque de civilizaciones de los años 90. La medida presidencial, aunque tiene carácter temporal, constituye una decisión discriminatoria, a la luz de los convenios internacionales y, en general, de las reglas del derecho internacional de los derechos humanos. La libertad de tránsito está consagrada como un derecho humano preeminente al que los Estados no deberían sustraerse a pesar de contar con la fuerza de la soberanía territorial para hacerlo. No cabe duda de que las relaciones internacionales, aquella ciencia que estudia los fenómenos y procesos políticos que acontecen en el mundo a partir de los impactos producidos por sus actores visibles — por ejemplo, los presidentes de las naciones del mundo-, sea positiva o negativamente, el día de hoy nos muestra un sistema internacional trastocado, donde dichos actores expresan constantes pugnas - por ejemplo, EE.UU. con México o EE.UU. con Irán-, tan solo por alcanzar y administrar el poder y la hegemonía. Así, pues, todo parece andar al revés, pues insólitamente en el Reino Unido, aliado histórico de Washington, más de un millón y medio de sus ciudadanos protestan por la próxima visita de Trump a este país.

Los últimos meses en el mundo vuelven a estar marcados por el terrorismo. Ataques en Londres y Manchester. Un coche bomba fuera del estadio del club turco Besiktas (29 muertos); un ataque suicida en un cuartel militar en Yemen, donde se libra una batalla sin cuartel por el poder central con la presencia de fuerzas de Arabia Saudí (40 muertos); otro perpetrado por el grupo terrorista Boko Haram en un mercado al noroeste de Nigeria (57 muertos); y la reacción del Estado Islámico en Palmira, Siria, donde habían retrocedido, aniquilando a por los menos 34 soldados del régimen de Bashar al-Assad. Está claro que el terrorismo se ha exacerbado y diseminado en el globo, mostrando su ferocidad más allá de las fronteras de los países islámicos en el Medio Oriente, como ha sucedido en Europa o Asia. La tildada parsimonia de los Gobiernos para frenarlo está alentando el resurgimiento de los nacionalismos, pero esta vez radicalizados, principalmente en el Viejo Continente, que buscan apurar los procesos, primero para tomar el poder a como dé lugar — Francia, por ejemplo- , y segundo, para adoptar medidas de reacción nunca antes vistas en aras de retornar al estado de paz global. El riesgo está en que pudieran confundirse con acciones represivas indiscriminadas que en nada se diferenciarían de los ataques terroristas. Así, pues, el extremismo o radicalismo ultraconservador de las derechas en diversas partes del planeta en nada se diferenciarían del extremismo fundamentalista islámico, y eso sí sería gravísimo. Una nueva colisión, esta vez 
no tradicional, como lo fue el conflicto entre Estados en la sociedad internacional del pasado, puede emerger incontrolable. La ONU debe haberlo sopesado, pero la lentitud de la comunidad internacional estaría superponiéndose.

Suma a lo anterior las declaraciones del reelegido presidente de Irán, Hasan Rohani, llamando la atención o, si se prefiere, advirtiendo a Estados Unidos de América sobre la soltada pretensión de que pudiera revisarse el acuerdo sobre el programa nuclear para Teherán, un asunto más serio de lo que algunos puedan imaginar. Irán no es cualquier actor de las relaciones internacionales. Se trata del país más importante e influyente de los Estados islámicos chiitas del Medio Oriente en términos de poder, y eso lo saben perfectamente Israel y Washington. El acuerdo nuclear al que arribaron los países miembros del Consejo de Seguridad (China, Francia, EE.UU., Reino Unido y Rusia) más Alemania no solamente demandó importante cuota de tiempo, sino que fue muy difícil concretarlo.

Los iraníes estuvieron de acuerdo y ese fue por sí mismo un importante logro, pues imponiéndosele un programa nuclear este país lograba liberarse de la carga de un conjunto de sanciones que no le permitían despegar económicamente. Rohani acaba de decir sin inmutarse que "Estados Unidos es nuestro enemigo", y esa aseveración no es un signo de tranquilidad para nadie viniendo de un país que mantiene y conserva un poder de contención para Occidente en esa región predominantemente convulsa. Desde la revolución islámica que lideró el Ayatola Ruhollah Musaví Jomeini, en 1979, volviendo al país en ese instante un Estado esencialmente teocrático, las relaciones entre Washington y Teherán nunca pudieron mantener un nivel alturado y/o de tolerancia. Al contrario, se afirmaron las relaciones de odio que tuvo un momento crítico durante la crisis de los rehenes de la embajada estadounidense en Irán (1979-1981).

Por lo anterior, el presidente Donald Trump deberá reflexionar y sopesar la importancia estratégica para EE.UU. del acuerdo logrado por el presidente saliente Barack Obama y la calificación que ha hecho del referido acuerdo llamándolo "catastrófico". Ahora deberá pensarlo dos veces. Está claro que los iraníes no van a aceptar ningún cambio en las reglas de juego, y eso también deberá sopesarlo el nuevo Gobierno instalado en Washington en enero de 2017.

El orden mundial está trastocado. Han pasado 16 años desde aquel 11 de setiembre de 2001 en que se produjo el mayor atentado terrorista que registra la humanidad. Nueva York, principalmente, y su centro financiero fueron el blanco perfecto de Al Qaeda, que actuó coludido con el Gobierno talibán de Afganistán. Ese día se acabó para siempre la idea de que EE.UU. era un país invulnerable e intocable, tal como lo pregonó el idealismo de su Destino Manifiesto en el siglo XIX, que los hizo creer elegidos e infalibles para liderar el mundo; sin embargo, en sus propias narices el golpe certero de Osama Bin Laden produjo un cambio radical en los paradigmas de las relaciones internacionales vigentes. 
Washington venía de emerger como la única superpotencia del planeta. Con la caída del Muro de Berlín (1989), había sido enterrada la Guerra Fría, y EE.UU. se encumbraba como la nación todopoderosa de la tierra. El imperialismo no solo económico sino militar lo hizo insuperable, y en esa confianza, en los años 90 cruzó el Atlántico y llevó adelante la Guerra del Golfo Pérsico. Pero la catástrofe humana de las Torres Gemelas, con más de 4500 muertos, modificó el tablero internacional acabando el corto período unipolar estadounidense para dar paso a una sociedad internacional donde el poder debía ser prorrateado, dando paso al mundo unimultipolar, que es en el que vivimos. EE.UU. debió comenzar a negociar con potencias emergentes como China y Rusia, que, por supuesto, negaron a Obama, desde el Consejo de Seguridad, bombardear Siria para acabar con el régimen de Bashar al-Assad. Los Estados, en consecuencia, que deben esforzarse por el mantenimiento de la paz conforme a la Carta de la ONU (1945), desde el denominado $11 \mathrm{~S}$ afrontan un fenómeno distinto: el conflicto no convencional al que nos hemos abocado en este ensayo y que ha llenado de hermetismo al planeta. Debemos asimilarlo, pues las guerras y alianzas entre Estados del pasado han cedido a las coaliciones para combatir al terrorismo internacional.

También agrega el reciente el reciente ensayo nuclear por misil balístico intercontinental realizado por Corea del Norte, el mismo que ha causado alarma en el mundo y tiene algunas llaves que hacen compleja una acción internacional para evitarla. El derecho internacional no funciona como el derecho nacional, donde los Estados cuentan con una autoridad central. Aunque sea difícil aceptarlo, en el mundo no hay un poder jurídico central. La ONU, que es el mayor foro de debate político, no lo es. Por esta razón, a diferencia de un Estado donde internamente las relaciones son verticales pues la autoridad se vale de normas jurídicas coercitivas (advertencia o amenaza) y coactivas (uso de la fuerza) para imponer sanciones a quienes infrinjan la ley, en la comunidad internacional las relaciones son horizontales, porque todos los actores son jurídicamente iguales. Por esa razón, además, EE.UU., Corea del Norte, Haití o el Perú son soberanos, es decir, no tienen que darle cuenta a nadie de sus decisiones unilaterales. Si algún otro Estado u organización internacional se inmiscuye en dichas decisiones, colisiona con el principio de no intervención en los asuntos internos de los Estados, consagrado en el derecho internacional. Como quiera que Corea del Norte es firmante de acuerdos internacionales sobre no proliferación de armas nucleares, lo único que puede hacer la ONU es emitir resoluciones que no tienen carácter vinculante u obligatorio. Sí, así como se lee. Solo son disposiciones en el nivel de recomendación. Ello explica que nada se pueda hacer — salvo sanciones económicas - frente a los ejercicios nucleares de Pyongyang, como tampoco nada pudo hacerse con los sonados ejercicios, también nucleares, realizados por Francia en los atolones de Mururoa y Fangataufa, en la Polinesia Francesa, a mediados de los años 90. Excepcionalmente, el Consejo de Seguridad (ONU) puede decidir el uso de la fuerza, pero eso es más complejo de lo que podamos imaginar. 
Hay que tener muchísimo cuidado con Pakistán, donde se producen un sinnúmero de atentados terroristas. Este país de más de 190 millones de habitantes, es el sexto más poblado del planeta, con el alarmante registro de ser el más violento en el mundo. De Pakistán, que es una república islámica con el sétimo ejército más numeroso de la tierra, cuya independencia solo data de 1947, cuando logró escindirse de la India, considerada su archienemiga en la región, salió librada la entonces niña de 12 años y hoy activista Malala, —Premio Nobel de la Paz 2014-, luego de que sufriera un atentado, también talibán, para impedirle ir a la escuela.

Como ya hemos referido a lo largo de este ensayo, el fundamentalismo islámico ha prosperado en esa región como en ninguna otra parte del orbe. Los talibanes se encuentran en Pakistán y en Afganistán, país con el que limita y de donde realmente surgió el referido fundamentalismo en la década de los años 90, en que aprovechando la retirada soviética de Kabul, tomaron el poder en el país. Los talibanes dominan toda la región de Waziristán, al norte del país, y no han desmayado su accionar para enfrentarse al régimen del primer ministro, el magnate Nawaz Sharif, en el poder desde el 2013. A diferencia del atentado del mes de marzo en la escuela de Peshawar, atribuido al Tehrik y Talibán Pakistán, el que acaba de suceder lo ha adjudicado el grupo extremista Jamaat-ul-Ahrar, una activa facción talibán. El Gobierno ha gastado en los últimos 10 años más de 80000 millones dólares para aplacar el terrorismo. Con 50000 muertos hasta la fecha, el debilitado y deficitario régimen hasta ahora no lo ha logrado, y el panorama advierte ser cada vez más sombrío.

Junto a Pakistán está el mayor desconcierto de la comunidad internacional en los últimos años: el terrorismo de los lobos solitarios a que ya nos hemos referido. Entendamos que el terrorismo internacional ya no puede ser identificado únicamente en los grupos extremistas como el Estado Islámico, Al Qaeda, etc., que ocupan las primeras páginas de los medios. Ahora los actos de terror incluyen a los denominados "lobos solitarios" —actúan por adhesión a las causas yihadistas-, como ha sucedido en Orlando, Niza y recientemente en Munich. Los esfuerzos políticos para minimizar el origen de los ataques buscando señalar a los autores como personas con problemas psicológicos o con crisis de naturaleza doméstica resultan un gravísimo error. La realidad no debe ocultarse. El atacante de Orlando que mató a 50 personas en una discoteca era un neoyorquino de padre afgano, el criminal de Niza que asesinó a 84 seres humanos era de Túnez, y el suicida de Munich que acaba de arrebatar la vida a 9 víctimas era de origen iraní. Ninguno de los tres tenía una conexión directa o indirecta con alguna organización fundamentalista.

Un serio trabajo de inteligencia puede inferir sin prejuicios que las motivaciones en los tres casos han tenido el mismo sesgo que ha llevado a los grupos terroristas a cometer sus acciones. ¿Cómo vencerlos? Por supuesto que la estrategia de los bombardeos o acciones coactivas que tanto ocupa a la coalición internacional, aquí no sirve de nada. La acción unitaria y aislada de los lobos solitarios resulta muy difícil de contrarrestar desde un puro esquema militar o policial. 
El asunto es muchísimo más complejo de lo que nos podamos imaginar. Aquí se trata de neutralizar el auge del pensamiento radical que anima a los atacantes, y para ello deberá ser importante un trabajo de filigrana desde adentro en la propia comunidad musulmana para enseñar las exactas verdades del islam y del Corán, que no tienen nada que ver con la violencia del terrorismo de origen islámico.

El orden mundial está en riesgo pero no solo por Corea del Norte. Ha llamado poderosamente la atención internacional la posibilidad de que el Estado Islámico pueda considerar entre sus acciones terroristas la de un componente nuclear. El presidente Trump seguramente convocará a los países que integran la coalición internacional que lidera Washington para acabar con el Estado Islámico, a una reunión en el marco de otra precisamente en que se abordará la amenaza del uso de armas nucleares. De confirmarse esa macabra posibilidad, lo que estaríamos viviendo hacia adelante es un estado de alerta máxima por las consecuencias que pueda ocasionar un atentado de esa dimensión. La amenaza es mucho mayor que la devenida del propio Gobierno de Corea del Norte, de cuyas pataletas el mundo ya está hasta acostumbrado.

En cambio, del Estado Islámico, hasta este rumor no confirmado, nada se sabía de una acción de esta magnitud. La razón del mayor peligro salta a la vista: el Estado Islámico no es un Estado, es decir, no es ninguna sociedad jurídicamente organizada que cuente con reconocimiento internacional; tampoco es una entidad admitida en la ONU. Nada de eso. El Estado Islámico es un grupo no convencional, es decir, un conjunto de gentes que se juntan para aplicar el terror por diversas razones y que no saben ni les interesa respetar los acuerdos internacionales o nacionales sobre conflictos; es decir, no saben firmar la paz, tampoco declarar la guerra, respetar a los prisioneros y enfermos y hasta a los civiles que no intervienen en los referidos conflictos. En ese sentido, atacar con una bomba nuclear - de contar con ella y estar en condiciones de hacerlo- no será cuestión difícil. Estaríamos ante un peligro de magnitudes insospechadas.

No se crea que las acciones violentas del Estado Islámico se realizan únicamente en el Medio Oriente. No. Una de las características de este grupo terrorista desde que apareció en el escenario internacional ha sido precisamente que sus operaciones se han ejecutado en distintas partes del mundo.

En los últimos meses hemos visto la seña de su expansión en Túnez, Francia, Bélgica, EE.UU., Egipto, Turquía y ahora le ha tocado a Indonesia, el Estado con el mayor número de musulmanes en el planeta (230 millones). Yakarta, su capital, había sido objeto de diversas amenazas en los últimos tiempos y más de una voz autorizada en el país subestimó la eventualidad de un ataque como el registrado en la víspera que ha dejado el lamentable saldo de siete personas muertas. Salta a la vista la enorme capacidad y logística con que cuen- 
ta el EI para mostrar la fuerza de su expansión. Tienen muy en claro que su actuación no puede limitarse a un solo territorio, y por eso escogen países con problemas de estabilidad, principalmente política y económica, o hasta Estados fallidos o ingobernables, que suelen ser los más vulnerables a la acción terrorista. En este país asiático formado por una multidiversidad de etnias y lenguas, la Yemma Islamiya, considerada el brazo armado de Al Qaeda, ha venido operando múltiples atentados a lo largo y ancho de Indonesia. Hay que admitir que el tamaño de estos siniestros cuesta muchísimo dinero, lo que se explica por el ingreso que obtienen del petróleo que colocan en el mercado negro asiático gracias al control de importantes refinerías del crudo en Medio Oriente, ubicadas en Siria e Irak, donde cuentan su mayor influencia.

En síntesis, el Estado Islámico (no convencional) y Corea del Norte (convencional) alteran el orden mundial, eso está claro. La tensión planetaria no es gratuita. Recordemos que un terremoto de magnitud 5,1 fue registrado al inicio de este año en Corea del Norte, y este suceso esta vez no ha sido producido por la naturaleza sino por el propio hombre. Su causa habría sido el estallido de una bomba de hidrógeno por el régimen de Pyongyang en la zona norte del país. Se trata de un ejercicio nuclear que superaría cualquier expectativa hasta ahora sospechada del dictador King Jong-un y que resulta una amenaza para la paz del mundo. El tamaño de su impacto es ciento por ciento superior a las bombas nucleares estalladas en las ciudades japonesas de Hiroshima y Nagasaki, en 1945, por cuyas consecuencias el impero nipón terminó por rendirse incondicionalmente, finalizando con ello la Segunda Guerra Mundial. Corea del Norte sigue siendo un completo misterio para la comunidad internacional.

La vida intraestatal es difícilmente conocida, y esta realidad no permite saber la dimensión de lo que realmente son capaces de realizar. Los esfuerzos de EE.UU. y de los demás miembros del Consejo de Seguridad de la ONU para persuadir a Irán que acepte los términos de una negociación para su programa nuclear ahora deberán inspirar a una acción en el mismo sentido para conocer y luego persuadir la mitigación del potencial nuclear del régimen totalitario norcoreano. Es probable que Washington esté evaluando la situación y opte por una actitud discrecional, dado que las reacciones del joven líder Jong-un pueden resultar impredecibles. Debemos considerar que todo puede ser una amenaza construida en base a la mentira, pero también que resulte una macabra verdad, de allí que debe actuarse con mucha cautela frente a uno de los regímenes más aislados e inciertos del planeta.

Se trata de la bomba del miedo. No cabe duda de que cuando el líder comunista norcoreano Kim Jong-un declara lo hace queriendo amenazar a la humanidad sobre la inminencia de atacar o invadir Corea del Sur o, como recientemente ha expresado, en el sentido de activar en cualquier momento una bomba de hidrógeno, una de las más mortíferas que jamás hubiéramos querido que la inteligencia humana tuviera la capacidad de construir. En 
la historia de su diseño trabajaron incansablemente dos físicos: Edward Teller, de origen húngaro-estadounidense, y el matemático polaco-estadounidense Stanisław Ulam, quienes recién en 1951 la terminaron de desarrollar. No voy a referirme al cálculo del tamaño de su impacto desde la física nuclear porque no lo entiendo, pero sí que su detonación sería el final de todo. Es toda una incógnita que la denominada bomba $\mathrm{H}$ o bomba termonuclear fuera desarrollada por países con capacidad tecnológica como la de Corea del Norte. Anunciar que la poseen sí que llama la atención. Puede obedecer a la estrategia del miedo que le ha dado resultados eficaces al régimen totalitario de Pyongyang. Nostradamus, aquel famoso vidente de siglos anteriores que anunció muchos sucesos desastrosos en el futuro para el mundo, dejó entrever que la propia humanidad se iba a autodestruir por esas ambiciones de poder de las potencias, de allí que la teoría de la involución humana no es descabellada, pues el propio hombre construye su propio destino. Es verdad que la mayoría de los habitantes del mundo queremos la paz, pero también que estamos plagados de psicópatas y desquiciados que con solo apretar un botón podrían cambiar la historia de la civilización.

El pánico cada vez se apodera más de las personas y hasta de los Gobiernos en el mundo. Estados Unidos ha lanzado una alerta en todo el planeta por la escalada de las amenazas terroristas y llama a sus ciudadanos a adoptar las máximas medidas de precaución. En estos momentos no existe lugar en el mundo que pueda ser calificado de seguro. No se trata de agudizar el estado psicológico que ha creado una atmósfera de incertidumbre colectiva de niveles planetarios. Nunca antes como ahora la sociedad internacional deberá afrontar un clima de inseguridad. Añádase a lo anterior, la seria crisis que deviene de la falta de una acción conjunta y articulada de la coalición internacional liderada por Washington.

Entre los Estados que forman la coalición internacional promovida por Estados Unidos para acabar con el grupo extremista Estado Islámico de Irak y el Levante que viene dislocando el statu quo de paz en el Medio Oriente, principalmente en los territorios de Siria e Irak, cunde por estos días cierto desencanto por la falta de eficacia para lograr el objetivo de acabarlo totalmente, aunque nadie desconoce los avances logrados para disminuir al yihadismo. Evidentemente, tendrán que realizar una reingeniería en la táctica militar conjunta para enfrentar al Estado Islámico. Las operaciones desde el aire con innumerables bombardeos contra los denominados blancos "estratégicos", que a la postre revelan ataques fortuitos a poblaciones civiles por el incremento del error, y los que últimamente han venido realizando por medio de drones, que son naves no tripuladas, no ha sido suficiente para conseguir los resultados esperados. Los terroristas se movilizan mucho más rápido que las fuerzas armadas de la coalición, mostrando mayor pericia sobre la geografía de la región, además de actuar de manera diseminada, confundiéndose con la población civil. En este tramo enteramente militar parece que hace falta la acción de infantería, que resultaría más efectiva. El mapa de influencia del 
Estado Islámico muestra un radio de influencia ampliado camino a la formación de un califato, que es su febril objetivo.

El mundo tiene prioridades según sus necesidades, y estas aparecen conforme se suceden los acontecimientos en las relaciones internacionales, que son por naturaleza diversos y cambiantes. En su momento fueron temas gravitantes el asunto de la pobreza y el hambre, el analfabetismo, la trata de blancas, los derechos humanos, el narcotráfico, el armamentismo, la corrupción y el cambio climático. Ahora, a la luz de todo lo que ha venido aconteciendo en el último medio año en París y Londres, nadie puede cuestionar que el terrorismo internacional, en todas sus manifestaciones, ha irrumpido violentamente en el desenvolvimiento de los Estados de tal manera que pareciera que ya no es tiempo de fijarse en las problemáticas interestatales que merecieron la mayor atención en su momento, sino que son los propios Estados los que ahora deben unirse para enfrentarlo como el mayor fenómeno no convencional del mundo.

El terrorismo internacional no respeta nada porque no es un actor convencional de las relaciones internacionales. Esto hay que reiterarlo. En el mundo todos los actores visibles que integran la denominada comunidad internacional se han organizado para vivir en armonía, respetándose unos a otros. El derecho, ciencia social que regula a través de normas jurídicas las conductas de estos actores visibles, establece las reglas de la convivencia entre Estados, y por esa razón existen tratados, convenios, pactos, acuerdos, etc. A estos actores los conocemos con el nombre de sujetos del derecho internacional, es decir, actores a los que se les puede atribuir derechos y prerrogativas, así como deberes u obligaciones. En otras palabras, a todos los actores convencionales, que son principalmente los Estados (sociedades jurídicamente organizadas), se les imputa responsabilidad y pueden y deben responder por sus actos, sometiéndose a las referidas reglas o normas jurídicas que incluso pueden sancionarlos. Así funciona el planeta; de lo contrario, todo sería un caos, es decir, una completa anarquía. Ello explica, además, por qué razón todos estos actores para consolidar la convivencia pacífica y coordinar una agenda común relativa a asegurar la propia existencia han alcanzado un alto nivel de organización, de tal manera que han sido capaces de ordenar sus relacionamientos en función de una agenda común con intereses también comunes, donde la actitud en sus interacciones está signada por la tolerancia. Así fue como los Estados construyeron en los últimos 400 años su carácter estatal impregnado de soberanía, un atributo intrínseco y exclusivo que los distingue de los demás actores que no la poseen. Los Estados crearon en las primeras décadas del siglo XX la Sociedad de Naciones o Liga de las Naciones, que luego, por su fracaso al no poder mantener la paz, fue reemplazada por la Organización de las Naciones Unidas, que desde 1945 tiene por tarea central el mantenimiento de la paz, conforme los propios Estados lo establecieron en la Carta de San Francisco, el mayor instrumento jurídico de la sociedad internacional contemporánea. Desde ese año, las relaciones internacionales 
estuvieron concentradas en evitar los conflictos entre los Estados, algo que recientemente ha cambiado.

El conflicto ha dado un tremendo giro. Ahora es la misma comunidad de Estados la que debe enfrentar uno nuevo: el fenómeno del terrorismo yihadista. Constituido en la mayor amenaza para el mundo, este actor no convencional ${ }^{10}$ porque no respeta las reglas del sistema internacional acordadas por la comunidad internacional bajo el amparo de las normas del derecho internacional está causando estragos a la paz y tranquilidad internacionales, y se vale del islam, la religión fundada por Mahoma en el $622 \mathrm{~d}$. C. ${ }^{11}$ para ocultar sus verdaderas intenciones de crear un escenario de terror permanente. Nadie puede ignorar que su impacto ha sido tan letal que el miedo y el pánico comienzan a hacerse pandémicos. Todo está asociado al imperio del terror. Nadie vive tranquilo. Las posibilidades de nuevos atentados son cada vez mayores y todos los rincones del mundo se han vuelto vulnerables. Todos hablan del extremismo islámico, pero nadie sabe explicar su origen. La gran mayoría lo asocia a un asunto religioso, pero la verdad es que la religión se ha convertido en el mejor pretexto para aligerar la práctica del terror. Como actores no convencionales de las relaciones internacionales que son Al Qaeda y el Estado Islámico de Irak y el Levante — solo por citar a los dos grupos terroristas que han concitado la mayor atención en la última semana-, saben que sembrando el terror están logrando que el planeta sucumba en sicosis y zozobra permanentes. No se les puede dar espacios, y por eso es necesario adoptar medidas conjuntas y globales. Los Estados deben dejar a un lado sus intereses o conflictos clásicos, y la ONU debe asumir un rol muy activo para enfrentarlos.

De allí que el yihadismo es una completa desnaturalización del islam, asume un estado de violencia fundamentalista y extremista injustificable, valiéndose de la sharia o ley islámica, también fanáticamente desnaturalizada, para mostrar su rechazo e intolerancia radical al cristianismo y, en general, a todo aquello que tenga que ver con Occidente (tesis de choque de civilizaciones - S. Huntington). ¿Qué explica, entonces, la matanza de 147 universitarios cristianos en la Universidad de Garissa, en el noreste de Kenia, a manos del yihadista grupo terrorista somalí Al Shabab?; o ¿por qué los extremistas del Estado Islámico decapitaron a 21 coptos cristianos en Libia, en este año?; o, finalmente, ¿qué ha llevado al Estado Islámico a masacrar a cientos de cristianos en la zona de Mosul, al norte de Irak, y a los que quedaron vivos, obligarlos a huir, convirtiéndolos en refugiados por su credo? El terrorismo islámico no es el islam de Mahoma, eso debe quedar claro. Hay que detenerlo de una sola manera: combatiéndolo con más medios que solamente las armas.

10 Robert Greene, Las 33 estrategias de la guerra (Barcelona: Espasa, 2012), 331-332.

11 Roger Caratini, Mahoma: la vida de un profeta (Buenos Aires: El Ateneo, 2003), 317-349. 
Tanto el Estado Islámico (actor no convencional) como Corea del Norte (actor convencional) están lacerando el orden mundial por medio del uso de mecanismos de terror que llevan a la comunidad internacional a un Estado de zozobra planetaria. La crisis del sistema internacional no puede doblegarse frente al terror, cualquiera sea su origen. Antes de que se produzca una diseminación por el planeta, es momento de neutralizarlo. La estrategia del poder internacional que se ve en la actuación de Estados Unidos junto a sus aliados tiene esa misión. Es el rol protagonista que Henry Kissinger siempre atribuyó a Washington, llamado a mostrar toda la fuerza de su poder político, económico y militar con el único objeto de asegurar la vigencia de su hegemonía, un pregón que lo dijo a cuanto presidente estadounidense ha conocido, ${ }^{12}$ desde el favorito Nixon hasta el inesperado Trump.

\section{REFERENCIAS}

- Aron, Raymond. "Paz y guerra entre las naciones". Revista de Occidente Bárbara de Bragan$z a, 12$ (1963).

- Barbé, Esther. Relaciones internacionales. Tercera edición. 2007.

- Caratini, Roger. Mahoma: la vida de un profeta. Buenos Aires: El Ateneo, 2003.

- Dougherty, James E. y Robert L. Pfaltzgraff. Teorias en pugna en las relaciones internacionales. Buenos Aires: Grupo Editor Latinoamericano, 1993.

- Greene, Robert. Las 33 estrategias de la guerra. Barcelona: Espasa, 2012.

- Kissinger, Henry. Diplomacia. Barcelona: Ediciones B, Grupo Z, 2010.

- Lewis, Bernard. La crisis del islam: guerra santa y terrorismo. Barcelona: Ediciones B, 2003.

- Mcmahon, Robert J. La Guerra Fría: una breve introducción. Alianza Editorial, 2009.

- Morgenthau, Hans J. La lucha por el poder y por la paz. Traducción de Francisco Cuevas Cancino y un grupo de estudiantes del Centro de Estudios Internacionales. Buenos Aires: Editorial Sudamericana, 1963.

- Rodríguez Mackay, Miguel Ángel. "El principio de solución pacífica de controversias como norma de ius cogens del derecho internacional y los medios de solución de controversias internacionales". En XLI Curso de Derecho Internacional 2014, dictado por el autor en el Comité Jurídico Interamericano de la Organización de los Estados Americanos (OEA), en

12 Henry Kissinger, Diplomacia (Barcelona: Ediciones B, Grupo Z), 2010. 
Río de Janeiro, 15 de agosto de 2014. Washington D.C.: Secretaría General de la OEA, 2015.

- Unal, Alí. El sagrado Corán y su interpretación comentada. Nueva Jersey: La Fuente, 2009.

- Waltz, Kenneth N. El hombre, el Estado y la guerra. Buenos Aires: Editorial Nova, 1959. 